\title{
REVIEW
}

\section{Animal models for osteoarthritis: processes, problems and prospects}

\author{
Kenneth P H Pritzker
}

Model systems are systems that are used to simplify complex phenomena and to understand otherwise elusive processes. ${ }^{1}$ An animal model for human disease can be defined as a homogenous set of animals which have an inherited, naturally acquired, or experimentally induced biological process, amenable to scientific investigation, that in one or more respects resembles the disease in humans. ${ }^{23}$

Elusive and complex as a precise understanding may be, virtually all definitions of osteoarthritis express the disease as transient and progressive structural changes in joint tissues, principally articular cartilage, subchondral bone, synovium, and synovial fluid. ${ }^{45}$ Articular cartilage oedema, fibrillation, and erosion accompanied by chondrocyte proliferation and decreased staining of matrix proteoglycans, subchondral bone thickening, deformation of the articular surface, osteophyte formation, synovial intimal cell hyperplasia, and synovial fibrosis are some of the standard features associated with osteoarthritis. These changes result from a poorly understood but very large series of functional events which may occur over a large fraction of the life of each affected individual. Biochemical, cell or organ culture models can provide information and insight concerning the mechanisms for functional events within cartilage, bone or synovium or selected cells within these tissues. These ex vivo models, inherently more highly controlled than animal models, are most useful for understanding short term biological events, and events isolated from the physiological influences of adjacent structures and general metabolism. As yet, ex vivo models cannot simulate the structural changes which occur in joint tissues in animals over months to years. Hence, animal models for osteoarthritis are required to study how the complex structural changes in tissues evolve over time, spontaneously or following experimental injury, and to determine how constitutive, environmental or biomechanical risk factors ${ }^{4}$ may initiate, promote, or otherwise regulate these changes (table 1). Animal models are also needed to show how therapeutic strategies may ameliorate, resolve or prevent osteoarthritis. ${ }^{6-8}$

The decision to use a particular animal model to study osteoarthritis is governed by criteria of relevance, appropriateness, and availability. ${ }^{3910}$ Relevance refers to the comparability of the phenomenon studied in animals to the corresponding process in human disease. Animals with characteristics similar to
Table 1 Osteoarthritis: constitutional and environmental factors

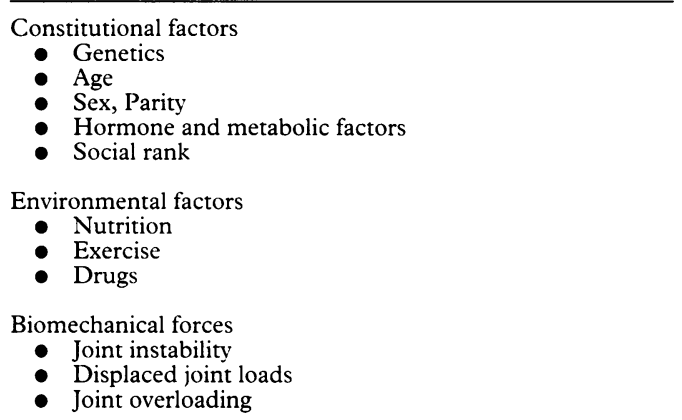

human disease as well as animals with features that differ in a known specific manner from human osteoarthritis may provide relevant models. Appropriateness refers first to the need to use animals rather than simpler models to investigate the process in question and second to the specific criteria that make one set of animals more appropriate than others for the experimental goals and objectives. Simplicity, predictability in reproducing circumscribed aspects of the disease, as well as the capacity to induce new insight, are appropriate factors when animal models are considered. ${ }^{9}$ For example, to test drug effects on an animal model, simplicity and predictability are paramount whereas to understand pathogenesis, a more complex model that more closely mimics human disease may be more appropriate. Availability criteria refers to practical factors such as adequacy of animal supply, the presence of controls, the ease of handling and environmental maintenance, as well as costs (table 2).

Table 2 Animal models for osteoarthritis: availability criteria

- Genetic homogeneity or heterogeneity

- Availability and homogeneity of nutrition and exercise history

- Life span of animal, time span of disease, age of onset

Disease frequency

- Availability of matched control population

Anatomical and physiological attributes

Quantitative

- Joint tissues sufficient for studies

- Adequate access to synovial fluid

Qualitative

Q Resemblance to human tissues

Weight bearing vs non weight bearing joints

Availability of experimental techniques for model

Supply of animals - standardisation

Ease of handling

- Access of model to experimental manipulation - Drugs

- Physical intervention

- Previous research in model (background knowledge, peer acceptance)

Costs 
Table 3 Development of animal models for osteoarthritis

1 Disease identification or induction in a set of animals

2 Availability of sufficient animals under experimentally controlled conditions

3 Characterisation of functional and structural similarities and differences between the model and human osteoarthritis

4 Testing hypotheses related to osteoarthritis aetiology, pathogenesis or therapy

There are several stages in the development of animal models for osteoarthritis (table 3). Firstly, the disease is identified or induced in a set of animals. With spontaneous disease, this may result from incidental comparative pathology observations or more rarely as with primate CPPD crystal arthropathy, from a deliberate search for the disease. ${ }^{11-13}$ Secondly, availability criteria must be considered. Animal models requiring colonies of large animals such as dogs or primates are available only within special facilities. Thirdly, the biological similarities and differences between the model and human disease must be demonstrated. Finally, when the model is well characterised, features of the model become useful to test hypotheses related to the pathogenesis or therapy of osteoarthritis.

Controlled investigation of structural changes in human osteoarthritic joints has severe limitations. ${ }^{101415}$ Humans with osteoarthritis have extensive genetic heterogeneity, and a varied nutritional, biomechanical, and pharmacological history, all of which can be only incompletely ascertained by epidemiological methods. Further, the lack of precise noninvasive methods to identify early disease, the relative inaccessibility of diseased tissues for sampling and even greater limitations in obtaining control tissues are obstacles to using human tissues for the study of osteoarthritis. ${ }^{16}$ This implies that to model the changes in joint organisation in osteoarthritis experimentally, a holistic system analogous to humans, namely animal models, is required.

Conceptually, by simulating osteoarthritic structural changes, animal models can demonstrate the sequence and specificity of each identified structural feature. By correlating the structural changes with putative systemic biological factors, the association of each factor with each change can be assessed. By manipulating the animal model pharmacologically or

Table 4 Animal models for osteoarthritis

\begin{tabular}{|c|c|c|}
\hline & Monoarticular & Polyarticular \\
\hline \multicolumn{3}{|l|}{ I Experimentally induced arthroses } \\
\hline \multicolumn{3}{|l|}{1 Biomechanical arthroses } \\
\hline Destabilisation models & - & \\
\hline Displaced biomechanical load models & $\bullet$ & \\
\hline Repetitive overload models & - & $\bullet$ \\
\hline \multicolumn{3}{|l|}{2 Structural arthroses } \\
\hline Surgical injury, for example, incision, excision & - & \\
\hline Trauma, for example, abrasion, contusion & $\bullet$ & - \\
\hline Physical & $\bullet$ & \\
\hline Chemical & $\bullet$ & \\
\hline Enzyme and cytokine activity & - & \\
\hline Drugs & $\bullet$ & $\bullet$ \\
\hline Nutrition & & $\bullet$ \\
\hline $\begin{array}{l}\text { Post inflammatory } \\
\text { (Transgenic animals) (?) }\end{array}$ & • & $\bullet$ \\
\hline \multicolumn{3}{|l|}{ II Spontaneous arthroses } \\
\hline $\begin{array}{l}\text { Spontaneous degenerative arthritis } \\
\text { (feral and wild animals) }\end{array}$ & & $\bullet$ \\
\hline \multicolumn{3}{|l|}{$\begin{array}{l}\text { Iaboratory bred species } \\
\text { Osteological and paleontological tissue }\end{array}$} \\
\hline human and other species & $\bullet$ & $\bullet$ \\
\hline
\end{tabular}

physically, factors that regulate the onset, progression, or control of osteoarthritis may be identified.

Although osteoarthritis affects other joints such as the intervertebral discs of the spine as well as synovial joints, models for spinal osteoarthrosis are beyond the scope of this review.

This paper discusses the types of animal models that have been used to study osteoarthritis affecting synovial joints, the features, advantages and disadvantages of each class of models, and the insights into an aetiopathogenesis that may be obtained from the study of selected animal models. The reports cited emphasise the advances of the past decade. For previous work see reviews by Gardner, ${ }^{17}$ Bentley, ${ }^{18}$ Arlet and Gédéon, ${ }^{19}$ Troyer, ${ }^{14}$ Adams and Billingham, ${ }^{15}$ Moskowitz $^{20} 21$ and more recently Altman and Dean. ${ }^{10}$

\section{Classes of osteoarthritis animal models}

Osteoarthritis models can be classified into two major groups, experimentally induced models and spontaneous disease models (table 4). On the basis of pathogenesis, Arlet and Gédéon divided experimentally induced osteoarthritis into two categories, mechanical arthrosis and structural arthrosis. ${ }^{19}$ Mechanical arthroses are induced by altering the amount and distribution of biomechanical forces on otherwise normal joint tissues. Structural arthroses are induced by physical, chemical, endocrine, biochemical or immunological alteration of one or more joint tissues. In this review, to emphasise the degenerative or non-inflammatory features, we will continue to use the term arthrosis to denote each class of model disease. To conform to current terminology, each particular model will be referred to as arthritis. To emphasise the role of the biological reaction to injury in the pathogenesis of mechanically induced models, we will refer to these models as biomechanical models. As described below, the concept of experimentally induced biomechanical and structural arthroses can be extended from monoarticular arthroses to include polyarticular models. As expected, spontaneous disease models are exclusively models of polyarticular disease (table 4).

\section{Experimental monoarticular osteoarthritis models}

As described in previous reviews, all experimentally induced monoarticular osteoarthritis models are essentially joint injury and repair models $^{10141517-21}$ (tables 5, 6). Common features of these models include the ability to define precisely the type of injury, the severity of injury as well as the time of onset and progression and to relate these events to markers of disease activity. Appropriate controls are readily available in the contralateral joint. However, as even local lesions may have systemic or biomechanical effects in the contralateral limb, controls from joints of age matched animals are preferred. The principal limitation of these models is that the experimental injury is induced over a short time 
Table 5 Experimental biomechanical arthroses

Monoarticular arthroses

1 Destabilisation models

- Patellectomy and patellar dislocation

- Ligament transection

- Meniscectomy \pm ligament transection

Tendonotomy and myectomy

Denervation

2 Displaced biomechanical load models

- Osteotomy

- Compression/immobilisation

Immobilisation

3 Joint overloading - chronic repetitive -acute

Polyarticular arthroses

- Overloading joints on hard surfaces

Overloading of immature joints

and is superimposed rapidly on normal joint structure at the age of the animal studied. These models are therefore particularly useful for understanding responses of joint tissues to specific injuries as well as for simulating the onset and evolution of secondary monoarticular osteoarthritis.

\section{Monoarticular biomechanical arthrosis} Monoarticular biomechanical arthroses are of two types: joint instability models and displaced biomechanical load models (table 5). The first joint instability models were induced by patella dislocation ${ }^{22}$ and patellectomy. ${ }^{23}$ These procedures in which extensive surgical disruption of the joint produced joint instability led rapidly to severe erosive and proliferative lesions of all joint tissues.

To study the development of lesions, joint instability models producing less severe injury and more gradual progression of degenerative changes were required. The first joint instability models meeting these criteria were established by Pond and Nuki ${ }^{24}$ who refined

Table 6 Experimental monoarticular structural arthroses

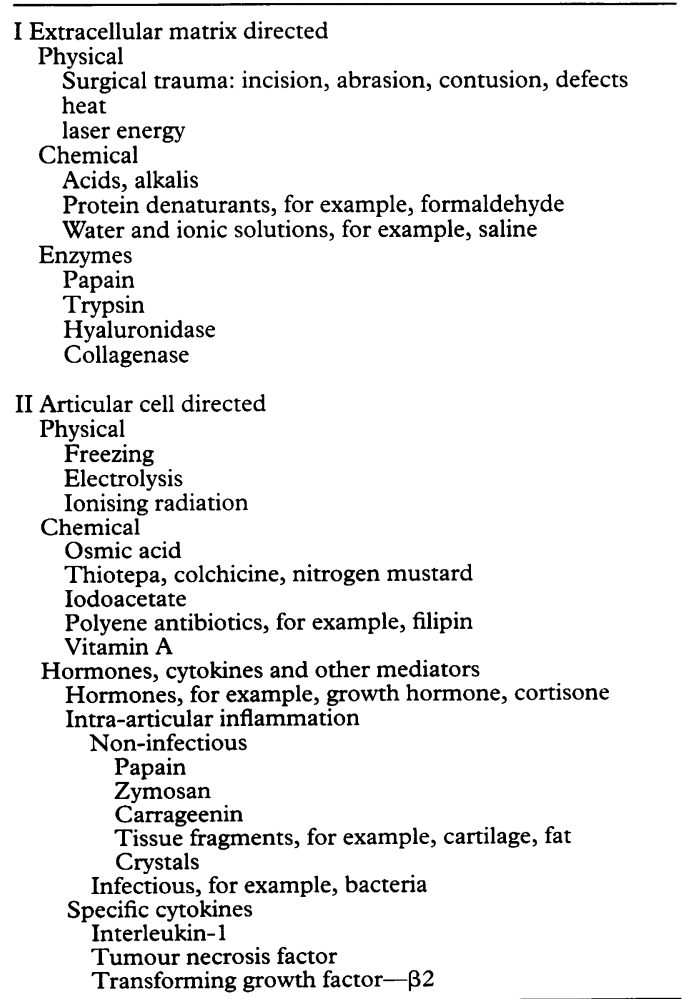

the canine knee joint anterior cruciate ligament transection model of Paatsama ${ }^{25}$ and by Moskowitz et al who developed the partial meniscectomy model in rabbits. ${ }^{26}$ Both models were stimulated by clinical observations that joint instability could lead to progressive degenerative arthritis. These models, their variants and successors initially produced joint inflammation and repair, particularly in cartilage and synovium. ${ }^{27-29}$ With continuing instability, erosive and proliferative changes in cartilage and subchondral bone developed that resembled changes in spontaneous osteoarthritis. ${ }^{27}{ }^{30-35}$ Although much more expensive, the advantages of the canine and sheep models over smaller animals include the increased amount of cartilage available for biochemical analysis, cell biology investigation, ${ }^{10}{ }^{33}{ }^{36-46}$ biomechanical studies ${ }^{47} 48$ and the ability to study long term changes in these animals with non invasive methods such as magnetic resonance imaging. ${ }^{33} 35$ Conversely, joint instability arthrosis in the rabbit and other small animal models may be more useful where large numbers of animals are required to study the effects of pharmacological agents such as oestrogen ${ }^{49} 50$ or glycosaminoglycan compounds $^{5152}$ on the regression of degenerative osteoarthritis. Particular variants have special applications. For example, as guinea pigs require exogenous vitamin $\mathrm{C}$, the effects of vitamin $C$ depletion and repletion can be studied by inducing joint instability lesions in this animal model. ${ }^{53} 54$ Immobilisation following intra-articular instability injury protects against development of degenerative arthritis. ${ }^{55} 56$ This demonstrates that joint instability coupled to shifting of normal loads can induce progressive lesions with features such as cartilage fibrillation, erosion, chondrocyte proliferation and marginal osteophyte formation that are similar to human osteoarthritis. With the intraarticular surgical instability models, there is evidence that the traumatic injury associated with the surgical procedure itself and the presence of haemarthrosis advances the development and extent of early lesions, in particular, synovitis. ${ }^{5758}$

In long term studies, haemodynamic and tissue diffusion compromise by synovial pathology may interfere with nutrition and metabolite clearance thereby promoting further articular degeneration. ${ }^{59}$ Bole and colleagues have shown that joint instability induced by the extra-articular procedures of myomectomy and tendonotomy can produce progressive degenerative changes in guinea pig cartilage and subchondral bone. ${ }^{6061}$ Sensory denervation in itself does not appear to induce degenerative arthritis. Denervation does accelerate degeneration in the canine anterior cruciate ligament transection model.$^{62}$ Corticosteroid therapy, by reducing the proliferative activity of synovial cells, chondrocytes and bone cells, can reduce the severity of joint lesions induced by anterior cruciate ligament transection. ${ }^{63}$

Displaced biomechanical load models are models in which degenerative changes in joints are induced by altering load distribution 
without decreasing biomechanical stability. Osteotomy, compression and immobilisation are examples of procedures which can redistribute joint loads. Tibial osteotomy imitating valgus deformity has been used in rabbits ${ }^{64}$ and dogs. ${ }^{65}{ }^{66}$ Histologically and biochemically the lesions appear much milder than instability lesions but do involve areas of both increased and decreased joint loading. In contrast, in studies by the same investigators, pelvic osteotomy produced more extensive degenerative changes in cartilage than anterior cruciate ligament transection. ${ }^{67}$ These studies indicate that under normal biomechanical conditions, joint tissues can adapt over time to mild and moderate shifts in ambient load distribution. Conversely, acute changes of load distribution may have deleterious effects in joint tissues subject both to decreased and increased loading.

Compression/immobilisation models of degenerative osteoarthritis were derived from studies of the previous orthopaedic practice in which joints were immobilised in forced fixed positions. ${ }^{68}$ With compression/immobilisation, excessive pressure and/or interference with synovial fluid flow induces chondrocyte necrosis and cartilage erosion, as well as proliferative changes in the adjoining less compressed cartilage. ${ }^{56}{ }^{69-71}$ These studies led to the recognition of the importance of joint motion to joint healing and to the development by Salter of continuous passive motion as a chondroprotective therapeutic modality. ${ }^{72} 73$

With pure immobilisation models, early events include synovial effusion with the presence of neutrophils. ${ }^{74}$ Subsequently, cartilage proteoglycan depletion with increased ${ }^{35} \mathrm{SO}_{4}$ uptake is observed indicating that proteoglycan synthesis is increased. ${ }^{71} 75-77$ Prolonged immobilisation, even if interrupted by periods of mobility results in progressive cartilage lesions such as matrix fibrillation and erosion. ${ }^{71} 7678$ Administration of exogenous growth hormone does not prevent the degenerative lesions but does accelerate restoration of cartilage integrity following remobilisation. ${ }^{79}$ In the dog, immobilisation leads to proteoglycan depletion that involves the contralateral joint indicating that systemic factors, such as decreased exercise, may be partly responsible for the changes rather than immobilisation itself. $^{80}$ These lesions are more severe with concomitant aspirin therapy. ${ }^{81}$ Prolonged immobilisation leads to cartilage erosion and extensive regional osteopenia. ${ }^{71}$ Remobilisation tends to limit and reverse the adverse effects of immobilisation. ${ }^{78} 8283$ Treadmill running exercise does not affect articular cartilage morphology in normal animals. Excessive exercise, however, following remobilisation accelerates the degenerative lesions in cartilage. ${ }^{74} 83$

More recent models have demonstrated degenerative articular changes with excessive forces both after repetitive axial joint overload in the presence of joint motion ${ }^{84-87}$ and after a known acute transarticular load. ${ }^{88}$ Rabbit joints subjected to passive motion and overloading develop degenerative, proliferative and remodelling changes in both cartilage and subchondral bone. ${ }^{85}$ Cartilage fibrillation, erosion, as well as articular plate remodelling can be induced in dog patellae six months after the application of an acute transarticular load to the knee joint sufficient to fracture the uncalcified cartilage and subchondral bone but leaving the calcified articular cartilage intact. $^{88}$

\section{Polyarticular biomechanical arthroses}

The anecdotal wisdom of livestock owners states that to prevent degenerative arthritis, horses should not be raced until the age of two years, and cow barns should have earth rather than concrete floors. ${ }^{89}$ Both ideas are rooted in the concept that repetitive impact loads should not exceed the capacity of articular skeletal tissues to dissipate the absorbed energy stored between each stress. Drawing from this folklore and from mechanical engineering principles, Radin and his colleagues studied scientifically the effects of repeated impact loads on the development of osteoarthritis. ${ }^{8486879091}$ Using sheep as a model, Radin induced articular cartilage and subchondral bone degenerative changes in animals exercised on hard concrete surfaces compared with control animals exercised on softer wood chip paths. ${ }^{90}$ Although multiple joints are involved in this arthritic process, this cannot be regarded as a generalised arthrosis as only joints subjected to the mechanical overload are adversely affected. ${ }^{90}$ These studies demonstrated that shear stresses from repeated impact loads can simulate the anatomical topology of osteoarthritic lesions such as fibrillation, horizontal fractures at the cartilage bone interface and thickening of calcified cartilage with tidemark reduplication. Fibrillations are in fact microfractures of articular cartilage. These lesions have a topological pattern identical to material failure in synthetic polymeric biomaterials. ${ }^{92}$ Animals with high repeated impact loads have more severe cartilage fibrillation than animals exposed to lesser loads. Further, rapid loading prevents the stress relaxation which occurs when water in cartilage flows away from high pressure areas. This results in transmission of greater forces to bone, stiffening the subchondral bone with eventual osseous microfractures. ${ }^{87}$ While the direct effects of shear stress in cartilage and bone appear well established, the role of mechanical determinants on chondrocyte metabolism including the capacity of chondrocytes to produce and secrete matrix modulating enzymes remains to be determined. Within six weeks of repeated impact loading, Walker et al demonstrated synovial lining cell hyperplasia and sub-synovial fibrosis without preceding synovial neutrophil exudation. ${ }^{91}$ These features closely resemble human osteoarthritis. The early onset of these changes suggest that factors such as degradative enzymes elaborated by synovial cells may contribute to cartilage degradation.

In summary, experimentally induced biomechanical arthrosis models are useful for 
simulating joint injury and repair. In selected models, a progressive degenerative arthritis can be modelled. Further, these models are useful to study both the adverse and beneficial effects of joint motion and joint loading on articular tissues.

\section{Experimental structural arthroses}

In contrast to biomechanical arthroses in which altered loads affect previously normal tissues, experimental structural arthroses are models in which the tissue composition of one or more structural components of joints is degraded. This structural alteration can adversely affect tissue mechanics resulting in increased susceptibility to injury and varying incapacity to complete the repair process. Structural arthroses can be monoarticular, confined to one tissue within a joint, for example, cartilage, or even restricted to one portion of a joint surface. Alternatively, local structural arthrosis models can be devised to affect tissues of an entire joint. In these models, the nature of the injury is controlled by the selection of the agent, the dose, and frequency of application. Polyarticular structural arthroses models either experimentally induced or identified as spontaneous disease in certain animal groups have been extensively investigated. As discussed below, the appropriate choice of model depends on the experimental question addressed.

\section{Monoarticular structural arthroses}

The vast range of noxious agents applied locally to joints bears testimony as much to the compositional strength and resilience of joint tissues, as it does to the breadth of investigators' imaginations or to the multitude of fallen hypotheses. ${ }^{10}$ 14-21 Traditionally, local structural arthroses have been classified on the basis of aetiologic agent, for example, physical, chemical, enzymatic, immunological etc (table 6). More useful is the assessment of these models based on the selectivity of their action on target tissues or tissue components. Some agents have activity directed broadly against extracellular matrix or articular cells. Newer agents can target more specifically matrix components such as collagen or proteoglycan or specific biochemical pathways within chondrocytes or synoviocytes.

Analogous to the inter-relationships of biomechanical forces and structural changes, injury to extracellular matrix may induce inflammation, repair, and other cell mediated responses. Conversely, agents directed towards articular cells affect the capacity to maintain, remodel or regenerate extracellular matrix. In selected models, such as surgical defects, ${ }^{93-95}$ abrasion, ${ }^{96}{ }^{97}$ contusion $^{98}$ or freezing ${ }^{99}$ of articular cartilage, the lesions can be induced in an anatomically focal and controlled manner. At their best, these models are particularly useful to investigate how chondrocytes replicate in vivo and regenerate their matrix.

\section{Models directed towards extracellular matrix and its components}

Depending on the particular model, matrix injury may involve tissue materials globally or may target selectively one or more matrix components. The simplest of these models is surgical trauma induced by incision, shaving, abrasion, ${ }^{9697}$ or contusion..$^{98}{ }^{100}$ While arguably these are micromechanical models, when abrasion is induced under some conditions, the heat energy generated degrades the subjacent matrix and causes regional chondrocyte necrosis. ${ }^{96}$ Surgical extirpation of tissues to create a defect is a useful model to study the regenerative capacity of joint components. For example, surgical lesions of cartilage that do not penetrate subchondral bone usually fail to generate reparative tissue. ${ }^{101} 102$ Defects that penetrate the subchondral bone induce chondrocyte regeneration from reparative fibrocartilaginous callus growing in from the marrow. Altman et al have shown that cartilage repair occurs following extensive cartilage abrasion to the subchondral bone and that the tissue repair more closely resembles hyaline cartilage in animals previously subjected to anterior cruciate ligament transaction than in animals that are subjected to abrasion alone. ${ }^{97}$ As anterior cruciate ligament transection initially produces synovitis, this suggests that the synovial reaction can modulate cartilage repair.

More specific markers are now available to track phenotypic expression of cartilage cells following injury. For example, the chondrogenic potential of reparative cells can be followed throughout the repair process as these cells stain with the S-100 antigen. ${ }^{103}$ Initially the matrix consists of a type I collagen rich fibrocartilage which under favourable conditions can remodel to hyaline cartilage composed of type II collagen. ${ }^{94}{ }^{104}$ With larger defects, progressive disruption of the joint surface occurs. ${ }^{93} 95$ Depending on the conditions, intra-articular administration of agents such as heat, fixatives, protein denaturants, acids, alkalis, distilled water or ionic solutions can degrade the matrix, adversely affecting or killing only superficial articular cells. ${ }^{17} 105$

Intra-articular administration of proteolytic enzymes such as papain, ${ }^{106-117}$ trypsin, ${ }^{118} 119$ hyaluronidase $^{120}$ and collagenase ${ }^{111} 115121$ are examples of model arthroses directed towards selective degradation of cartilage matrix components. At low doses, papain degrades proteoglycan transiently and spares the collagen framework. Within 48 hours there is acute synovial inflammation, cartilage proteoglycan depletion and chondrocyte necrosis. Subsequently cartilage oedema, proteoglycan regeneration, synovial cell and chondrocyte replication are features. ${ }^{112116}$

In this model, the capacity for complete repair can be shown to depend on cartilage collagen meshwork integrity. ${ }^{113}$ The mechanism and specificity of these models particularly papain and trypsin arthropathy must be questioned as early in the model, an inflammatory arthritis, which is dose dependent may 
be a feature. This inflammation can be reduced by agents such as glycosaminoglycan-peptide complex. ${ }^{122}$

In joints with surgically induced defects, chondrocyte regeneration can be enhanced by intra-articular administration of trypsin and blood. ${ }^{118}$ Intra-articular hyaluronidase injection produces degenerative changes in superficial cartilage, non-inflammatory synovial effusion, and striking hyperplasia of the synovial lining cells. $^{120}$ With more potent enzymes such as collagenase, there are associated degenerative changes in structures such as ligaments. This suggests that both direct effects on cartilage matrix degradation as well as instability caused by ligament matrix injury may contribute towards chronic articular degeneration in affected animals. ${ }^{111} 115$

\section{Models directed towards articular cells}

Models directed towards inhibition of articular cells, predominantly chondrocytes, can be induced by physical agents such as freezing, electrolysis, or ionising radiation similar to that following intra-articular injection of ${ }^{90}$ Yttrium $\left({ }^{90} \mathrm{Y}\right) .{ }^{123}$ Chemical agents such as intra-articular injection of the cytotoxic drugs Thiotepa, nitrogen mustard, ${ }^{17}{ }^{124}$ colchicine, ${ }^{125}$ osmic acid, ${ }^{126}$ or iodoacetate ${ }^{17115127}$ are capable of damaging articular cells selectively. For example, osmic acid, a fixative that has been administered intra-articularly for the therapy of rheumatoid arthritis, clinically and experimentally induces synovial fibrosis and functional impairment of residual synovial cells which contain osmic acid intracytoplasmic inclusions. ${ }^{126}$ Critical to the tissue effect of a chemical agent is its ability to penetrate cartilage matrix. Hence osmic acid and colchicine are most active in synovium whereas an agent such as iodoacetate which diffuses into cartilage affects chondrocytes. The cell cycle of the target cells at the time of injury is also important. Under normal conditions, chondrocytes are in a non-proliferative phase of the cell cycle and may be resistant to agents which affect proliferating cells selectively. Other agents such as vitamin A, ${ }^{128}$ and Filipin, ${ }^{129} 130$ by labilising cell membranes including those of lysosomes, stimulate chondrocytes to produce and secrete matrix proteolytic enzymes. ${ }^{18}$

Postinflammatory degenerative arthritis can be induced by intra-articular injection of agents which range from well defined compounds such as croton oil, ${ }^{131}{ }^{132}$ autologous lipid, ${ }^{133}$ carrageenin, ${ }^{134-136}$ zymosan ${ }^{137-139}$ and dextran sulphate ${ }^{140}$ to complex substances such as allogenic cartilage particles ${ }^{141}$ or organisms, principally bacteria. ${ }^{142}$ Moreover, as noted above, agents such as papain which are primarily directed towards matrix components may incite joint inflammation as an early event in their activity. ${ }^{116}$ Usually the inflammatory arthritis induced by these agents occurs for a very limited time. Following inflammation, a chronic degenerative arthritis may ensue. Mediators of articular tissue degeneration in this form of arthritis are difficult to identify. Also, lesions induced by these methods result in complex changes affecting both matrix and endogenous articular cells such as chondrocytes, synovial lining cells and subchondral bone cells.

These considerations have led to more controlled models in which specific biological mediators such as interleukin-1, tumour necrosis factor, substance $P$ or transforming growth factor- $\beta-2$ (TGF- $\beta 2$ ) are injected intraarticularly. ${ }^{143-146}$ Intra-articular interleukin-1 injection in C57/BL/10 mice produces cartilage proteoglycan degradation and suppression of cartilage proteoglycan synthesis without antecedent inflammation. ${ }^{144}$ These effects are prolonged in older animals. In these models, interleukin-1 (IL-1) has a more direct effect on proteoglycan synthesis inhibition than stimulation of proteoglycan degradation. ${ }^{147}$ As matrix degradation following IL-1 injection is mediated by metalloproteinases, this model has been used to determine the protective effect of serine proteinase inhibitors such as protease nexin-1 (PN-1) on cartilage proteoglycan content. ${ }^{148}$ Elford et al, injecting TGF- $\beta 2$ into rabbit knee joints induced synovial fluid and cartilage oedema, loss of cartilage matrix proteoglycan and synovial cell hyperplasia. ${ }^{145}$ As these effects were produced without an increase in interleukin- $1 \alpha$ synthesis, this suggests that TGF- $\beta 2$ can act directly as a mediator of joint damage. Models of this type have the promise of inducing specific cellular activities, thereby providing models to study articular cell regulation by endogenous or exogenous agents.

The role of calcium apatite or calcium pyrophosphate dihydrate crystal deposition in osteoarthritic cartilage remains controversial. The few available experimental models are difficult to relate to human disease. Reginato and Schumacher reviewed models in which calcium apatite was deposited in joint tissues. ${ }^{149}$ Systemic vitamin D and repeated intra-articular corticosteroid administration can both produce calcium apatite deposits in rabbit articular cartilage. ${ }^{149-153}$ These models are of considerable clinical importance as cartilage matrix proteoglycan biosynthesis is suppressed by corticosteroids but is restored following cessation of these agents. ${ }^{152}$

Corticosteroid arthrosis appears to model the calcium apatite deposition which occurs spontaneously in the cartilage of old rabbits. ${ }^{154}$ At present, no experimental method is available to induce calcium pyrophosphate dihydrate crystal deposition in articular cartilage.

An old but instructive example of local structural arthrosis is the model induced by the intra-articular injections of saline. ${ }^{105}$ This model has recently been used by Vasilev et al ${ }^{155}$ to study chronic synovitis beyond one month following injection. Two morphological features of chronic osteoarthritis, synovial lining cell hyperplasia and intrasynovial fibrosis develop within 60 days following intra-articular saline injections. ${ }^{155}$ Although the specificity of these changes for osteoarthritis has been questioned, ${ }^{17}$ Soren has shown that without lymphocytic inflammation, these synovial features are characteristic of degenerative arthritis. ${ }^{156}$ 
As models for the effects of synovitis and its sequelae, intra-articular injection of urate, calcium pyrophosphate dihydrate or cholesterol crystals have been used. ${ }^{157}$ The effects of prolonged and more extensive synovitis can be studied by intra-articular injection of biologically non-degradable crystals such as magnesium tetrasilicate (talcum powder). ${ }^{158-160}$ The prolonged inflammatory effects of this agent involves mediators which activate cartilage and bone remodelling. Thus intraarticular crystal arthritis models should be regarded as a spectrum that include pure synovitis models, for example, urate, CPPD or cholesterol, and inflammation-cartilage degeneration models, such as, talcum powder injection.

\section{Polyarticular structural arthroses}

Spontaneous osteoarthrosis in humans is commonly manifested as polyarticular disease. ${ }^{161}$ This suggests that metabolic factors drive the pathogenesis of this disorder. Despite its prevalence, identification of human generalised osteoarthritis particularly in its early stages remains difficult. Therefore model polyarticular structural arthroses may be particularly valuable to elucidate the key features of early osteoarthritis and to understand the genetic, nutritional and other factors that result in degenerative articular disease. There are two classes of models for polyarticular structural arthroses (table 7). Firstly, there are experimentally induced models in which a specific agent induces lesions with similarities to human osteoarthritis. Secondly, models can be developed from the study of spontaneous degenerative arthritis in animals. In these models, as in human osteoarthritis, the aetiological agent(s) and pathogenic mechanisms remain unknown.

\section{Experimentally induced polyarticular structural arthroses}

After the introduction in 1949 of cortisone for the treatment of rheumatoid arthritis, extensive research on the production and attenuation of arthritis was undertaken using a variety of

Table 7 Polyarticular structural arthroses

\begin{tabular}{l}
\hline Experimentally induced arthroses \\
Cholesterol feeding \\
Omega-fatty acid feeding \\
Quinolone antibiotics and derivatives \\
Hydralazine \\
Autoimmunity \\
Cartilage proteoglycan \\
Type II collagen \\
2 Spontaneous polyarticular arthroses \\
Mouse (mus musculus) \\
C57 Bl \\
STR/IN \\
NZY/BL \\
ICR \\
SAMP-3 \\
Rat (Rattus rattus) \\
CD/BR Sprague Dawley \\
Guinea pig (Cavia porcellus) \\
Dog (Canis familiaris) \\
Labrador retriever \\
Beagle \\
German shepherd \\
Primates \\
Rhesus monkey (Maccaca mulatta) \\
Human (Homo sapiens) \\
\hline
\end{tabular}

endocrine ablations and supplements. ${ }^{17} 2021$ As useful as these studies were then, because of the lack of purity of endocrine extracts, frequency of inflammation, intercurrent infections and short time course of experiments, their relevance to clinical joint disease should be questioned.

The principle that nutritional and endocrine manipulation can promote the development of degenerative arthritis was demonstrated by the studies of Ruth Silberberg and colleagues. ${ }^{162-172}$ $\mathrm{C}_{57} \mathrm{Bl}$ mice fed a high fat diet supplement, more specifically $4 \%$ cholesterol, developed knee and spine arthritis. ${ }^{168} 169$ Similarly the dietary substitution of Omega-3 fatty acids (Menhaden fish oil) for Omega-6 essential fatty acids (Safflower oil) produced cartilage fibrillation and ultrastructural retrogressive changes in rat chondrocytes. ${ }^{173}$ An acute degenerative arthritis, interesting for its specificity to a particular region of cartilage, can be induced in immature animals by oral administration of quinolone analogues. ${ }^{174} 175$ These drugs cause necrosis in the mid zone of articular cartilage where chondrocytes are replicating. This results in oedema which simulates the chondromalacia observed in the patella of adolescent human adults. Although the mechanism of this arthropathy is imperfectly understood, quinolones preferentially concentrate in the mid zone of immature articular cartilage. These agents bind specifically to circular DNA. It has been suggested that chondrocyte necrosis in this model is induced by the toxic effects of quinolone on chondrocyte mitochondrial DNA. ${ }^{174}{ }^{175}$

Polyarthritis induced by autoimmunity relates primarily to rheumatoid arthritis pathogenesis. Nonetheless, there is considerable interest in how immune responses to cartilage degradation products such as Type II collagen and proteoglycan promote the progression of degenerative arthritis. ${ }^{176-184}$ The observations in these experimental disorders indicate that primary immunologically induced arthritis produces tissue effects substantially different from other models of osteoarthritis.

\section{Spontaneous polyarticular structural arthroses}

Spontaneous osteoarthritis models include types of spontaneous degenerative osteoarthritis that occur in species other than humans $s^{130} 162 \quad 185-196$ as well as studies of paleontological and osteological remains from humans and other species. ${ }^{197-200}$

The isolated occurrence of degenerative arthritis in an animal or a group of animals does not in itself constitute an experimental arthritis model. ${ }^{89} 201202$ While degenerative arthritis appears widespread amongst mature livestock and domestic animals, these groups are not usually available for research. ${ }^{89} 203$ Similarly, degenerative arthritis may occur commonly in feral or wild animal species. However, when these animals are incapacitated even slightly by arthritis, they are more likely to be available to predators than investigators. Thus the study of spontaneous degenerative arthritis 
has been confined to laboratory bred colonies of mice, rats, guinea pigs, dogs and more recently, rhesus monkeys. ${ }^{130} 162$ 185-187 189-196

Sokoloff, noted that degenerative osteoarthritis is rare in rats. ${ }^{204}$ It can be speculated that this phenomenon relates to the observation that most rat species retain functional epiphyseal cartilage throughout life. Consequently rat articular cartilage may have a less mature, more resilient composition than cartilage of other species. Recently Sokoloff's observations have been challenged by Mohr and Lehmann who studied the ankle joints of CD/BK Sprague Dawley rats, aged approximately 26 months. Histological features of osteoarthritis such as chondrocyte necrosis, cartilage fibrillation and subchondral bone plate remodelling were commonly found in these joints. ${ }^{196}$ These investigations indicate that aged rats can be susceptible to osteoarthritis. However, the ankle joint is an unusual site as it is relatively spared in human disease.

Degenerative arthritis in laboratory bred mice has been extensively studied in the $\mathrm{C}_{57} \mathrm{Bl}^{162-167}$ 170-172 $^{17}$ and STR/NN ${ }^{185-187} 205-207$ strains, the NZY strain ${ }^{188}$ and in temporomandibular joints of $\mathrm{ICR}^{208}$ and $S A M-\mathrm{P} / 3$ strains. ${ }^{209}$ In some models such as the substrain of $\mathrm{C}_{57} \mathrm{BL} / 6$ mice ultrastructural morphological abnormalities are evident in the superficial articular cartilage as early as two months of age. ${ }^{210}$ Studies of genetically well defined murine models have been particularly suitable to demonstrate sex differences (male predominance), nutritional, and hormonal effects as well as the polygenic inheritance of degenerative arthritis. Limitations include the short life span of animals (circa two years), ${ }^{211}$ and the male compared to female predominance found in human polyarticular osteoarthritis. Further limitations include lack of correspondence of some morphological changes to human disease, ${ }^{171}{ }^{186}$ and the small amounts of tissue available for study in each animal. Walton has ascribed the degenerative arthritis in STR/IN mice to biomechanical factors, namely joint instability related to a propensity for patellar dislocation. Surgical stabilisation of the patella in these animals eliminated the development of osteoarthritis in the medial femoral/tibial compartment. ${ }^{185} 192205$

Recently the temporomandibular joints of two further murine strains, ICR and SAM-P/3 (Senescence accelerated mouse-prone) mice have been studied. ${ }^{208} 209$ Quite apart from difficulties relating temporomandibular changes to other synovial joints, there is a lack of distinction between ageing and degenerative arthritic features in these animal studies.

Erosive and proliferative changes in cartilage with osteophyte formation has been observed in guinea pigs. ${ }^{189} 212213$ The cartilage lesions are usually mild. Accelerated spontaneous degenerative joint disease which is often associated with hip dysplasia has been observed in breeds of large dogs. 190194195214215 Lust et al have shown that compared with human osteoarthritis, the cartilage changes in a colony of Labrador retriever dogs appears relatively mild. Nonetheless, cartilage from osteoarthritic animals differs biologically from controls particularly in fibronectin content. ${ }^{215}$ Without hip dysplasia, degenerative arthritis occurs in old Labrador retrievers, as well as other canine species such as German shepherds and Beagles with a prevalence at necropsy of 35\%. ${ }^{130} 195216$ Because of the presence of spontaneous degenerative joint disease in such species as guinea pigs and dogs, caution is required to interpret long term observations following experimentally induced biomechanical arthrosis such as anterior cruciate ligament transection in these animals. ${ }^{33} 35217$ Two forms of degenerative arthritis, calcium pyrophosphate dihydrate crystal deposition disease $e^{12} 218$ and osteoarthritis ${ }^{13} 219$ have been demonstrated in the rhesus macaque (Maccaca mulatta). While frequent in the most elderly animals, the difficulty of identifying early CPPD crystal deposition disease clinically has to date precluded the development of this species as a model for crystal deposition disease. In contrast, osteoarthritis appears in these animals following epiphyseal closure and progresses throughout life. The model is amenable to study as the disease has a high prevalence, age matched controls are available, the animals are free ranging, and the matrilineages can be clearly identified. ${ }^{13219}$ Further, the joints are sufficiently large to be suitable for radiological studies including MRI, ${ }^{220}{ }^{221}$ biochemistry, and histology ${ }^{191}{ }^{193}$ (figs 1-4).

Osteoarthritis in the rhesus macaque develops from the age of five to 15 years, an accelerated process compared to humans but sufficient to develop structural, chemical, and biochemical $^{13191193219220}$ changes in joints that closely resemble the features of polyarticular osteoarthritis in humans. Because of the extended time over which the osteoarthritis develops, this model is particularly suitable for the study of changes in cartilage collagen. As the organisation and distribution of cartilage collagen may be critically important to the

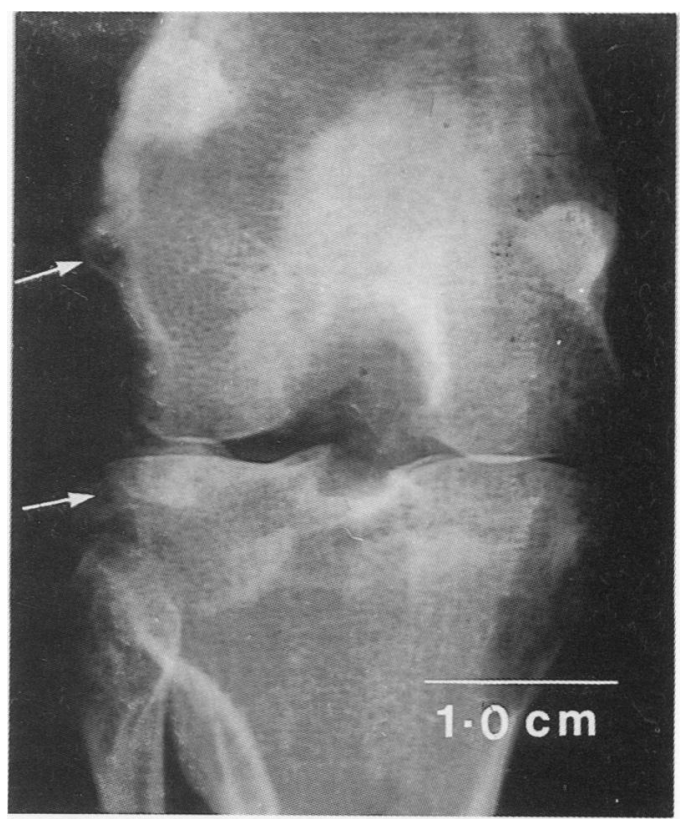

Figure 1 Anterior-posterior radiograph of rhesus macaque knee joint with osteoarthritis. Note joint space reduction, subchondral bone sclerosis and marginal osteophytes ( $\mathrm{D}$. 


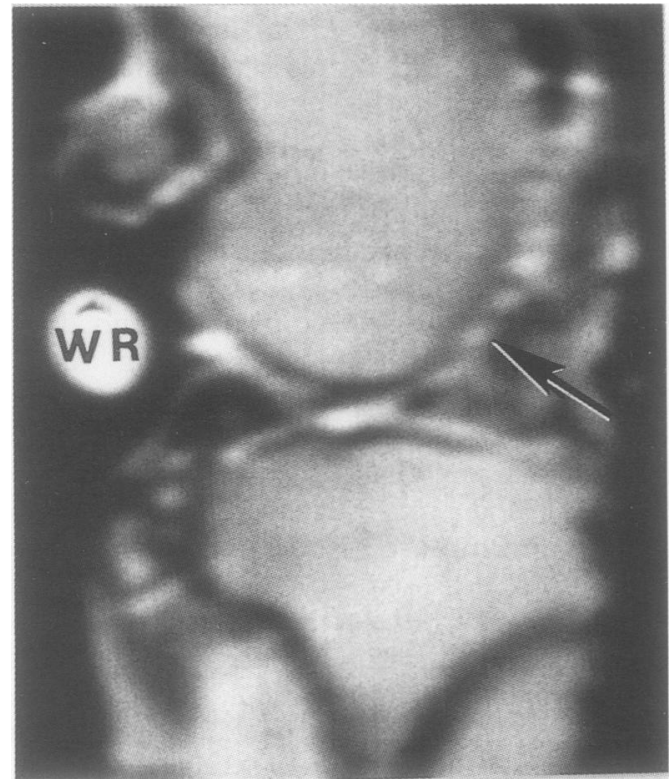

Figure 2 Parasagittal proton density MRI of rhesus macaque osteoarthritic knee joint. Note the thinning and disruption of articular cartilage particularly on the anterior femoral condyle ( $\mathrm{D}$.

$W R=$ external water reference.

progression of osteoarthritis, this model may be particularly useful for assessing these changes. ${ }^{20}$ Because of similarities of rhesus macaque physiology to humans, this model may prove particularly valuable for demonstrating the role of systemic factors including the role of obesity in the development of degenerative arthritis. The tropical location and the vegetarian diet (Monkey Chow) ${ }^{222}$ of these animals indicates that the degenerative arthritis can develop spontaneously independent of temperate weather or human eating habits. Two special resources for this model are concurrent social anthropological

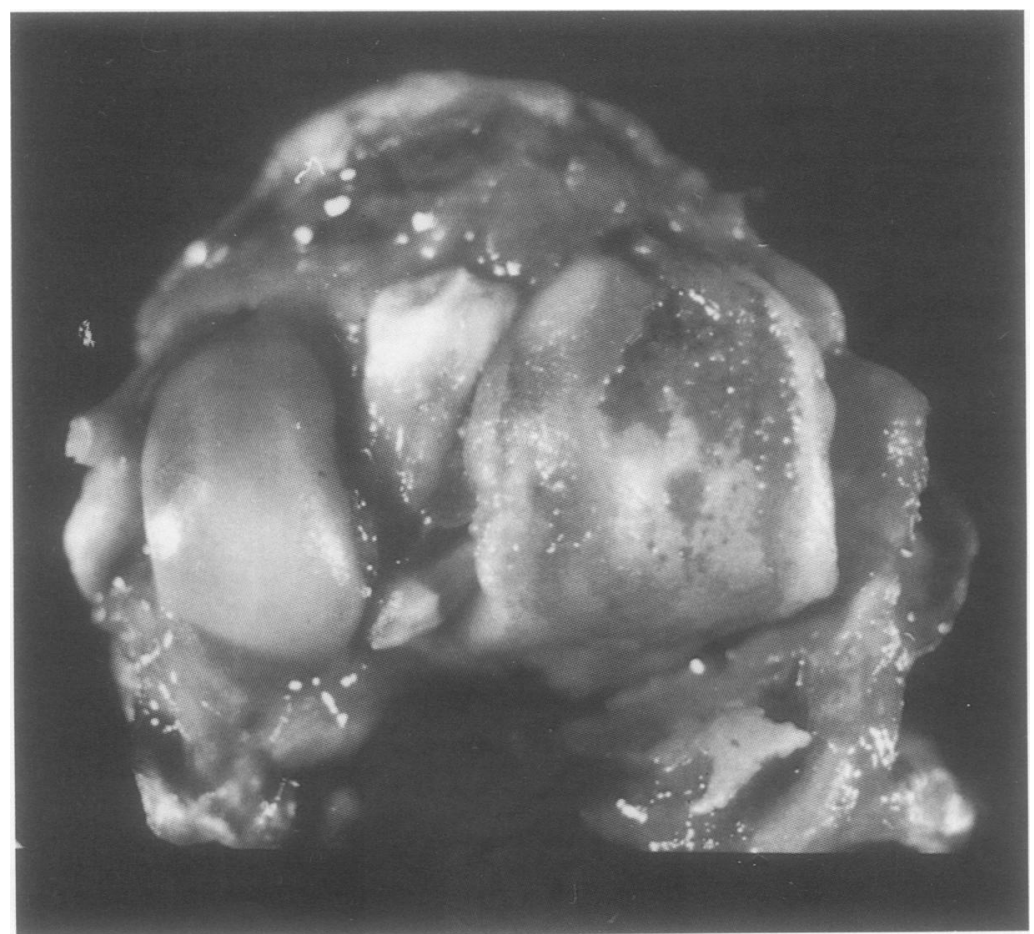

Figure 3 Femoral condyle of an osteoarthritic rhesus macaque. Note the loss of cartilage, bone eburnation and articular surface deformation on the medial condyle.

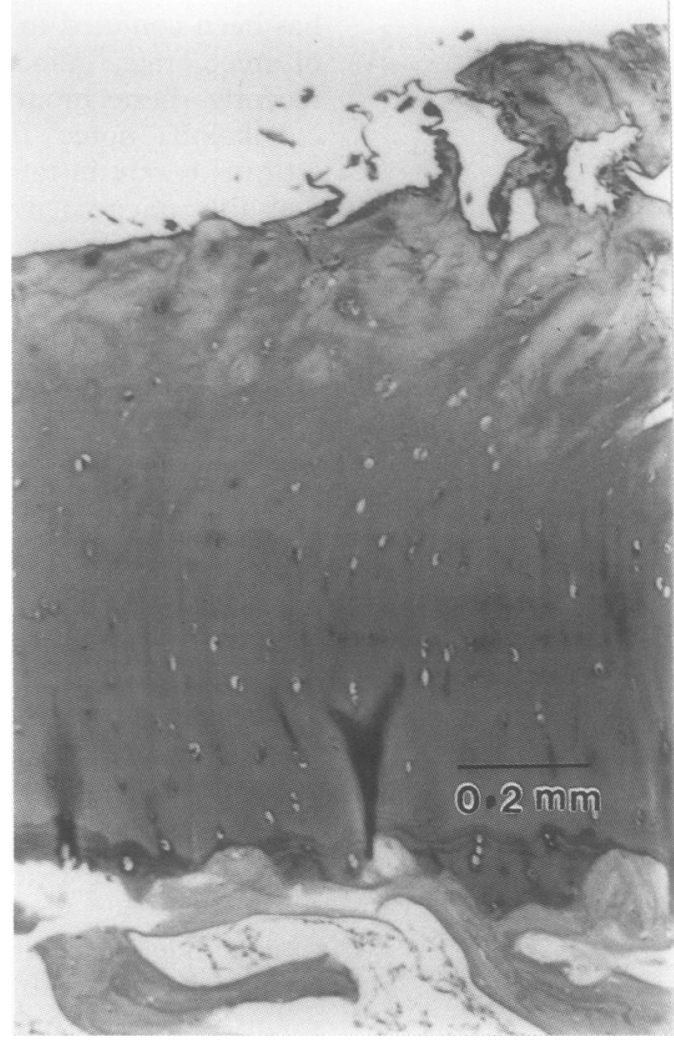

Figure 4 Photomicrograph of articular cartilage from an osteoarthritic knee joint of a rhesus macque. Note the fibrillation, erosion and loss of staining of the superficial cartilage matrix.

Toluidine blue stain magnification $\times 100$.

studies in the colony ${ }^{223} 224$ and the preservation of osteological remains from the entire population. ${ }^{198} 199$

While social correlates in this model remain to be determined, on the basis of osteological studies in this and other rhesus monkey populations, deRousseau identified the presence and demonstrated the prevalence of osteoarthritic lesions. ${ }^{198} 199$

The value of osteological studies to demonstrate the prevalence, nature and severity of degenerative arthritic lesions has been shown by Rothchild. ${ }^{197}$ These studies indicate that osteoarthritis is a disease of antiquity in humans and that degenerative joint disease occurs widely in both Old World and New World primates as well as other species. ${ }^{197}$ Osteological studies of prehistoric human populations such as the Inuit have provided insight into physical activity induced monoarticular and auciarticular forms of degenerative arthritis. Presumably this study reflects osteoarthritis resulting from displaced joint loading. ${ }^{225}$ Currently the utility of osteological models is hampered by the lack of precise correlation of osseous observation with soft tissue and cartilage features as well as the differing terminology amongst osteology, radiology and pathology disciplines.

\section{Cross-over or mixed models}

A promising application strategy for osteoarthritis models involves the controlled use of one model within another. This approach is not new. For example, administration of 
high fat diets, ${ }^{163168169}$ or testosterone $e^{164165167}$ to $\mathrm{C}_{57} \mathrm{Bl}$ mice that constitutionally develop degenerative joint disease, accelerates the severity of the arthritis. Recently, Bendele et al studied the effects of iodoacetate, a chondrocytotoxic compound administered intraarticularly before partial meniscectomy or collateral ligament sectioning in the guinea pig model of osteoarthritis. ${ }^{127}$ No differences were observed in the cartilage of iodoacetate treated groups compared with controls. This suggests that chondrocytes do not contribute actively to the initial reaction of instability induced injury. Altman et al studied the effects of full thickness chondral abrasion in the Pond-Nuki model of anterior cruciate ligament transection. They demonstrated that cartilage repair in the presence of instability was facilitated by exposure to subchondral bone that resulted from abrasion. ${ }^{97}$

Carney et al using the Pond-Nuki model of anterior cruciate ligament transection studied proteoglycan biosynthetic properties of cartilage explants in culture. ${ }^{226}$ Cartilage proteoglycan synthesis following ligament transection showed quantitative differences both in proteoglycans synthesised and in breakdown products. ${ }^{227}$ This suggests that chondrocytes in these animals have undergone phenotypic changes which can persist under ex vivo conditions. Mixed models have shown that after arthritis is induced, cartilage cells can maintain new phenotypic characteristics ex vivo. For example, Schalkwijk studied cartilage from $\mathrm{C}_{57} \mathrm{Bl} / 10$ mice with arthritis induced by intraarticular zymosan injection. Chondrocytes from the affected animals were more resistant ex vivo to the anabolic effects of insulin-like growth factor-1 (IGF-1). ${ }^{138}$

\section{Animal models for osteoarthritis: prospects}

In his monumental review of experimental arthritis published in this journal in 1960, Dugald Gardner pointed out that although numerous experimental models for arthritis had been employed for over a century, none was strictly mimetic for human disease. ${ }^{17}$ Recently, Leon Sokoloff has suggested that the value of animal models must relate to the correspondence of structural and functional features within the model to those of human disease. ${ }^{28}$ This task is especially difficult for osteoarthritis. As Sokoloff points out, osteoarthritis remains broadly defined as a heterogenous group of disorders, causing progressive degeneration of joint tissues. Without visible anatomical lesions, such definitions do not distinguish differences in tissue composition associated with osteoarthritis from those associated with ageing, or from reactions to biomechanical, toxic, or inflammatory injury.

Cartilage hypertrophy following anterior cruciate ligament transection provides a currently controversial example of tissue compositional change in an animal model. The controversy resides in whether cartilage hypertrophy relates to oedema following acute injury, to repair, or to progression of osteoarthritis. $^{32} 3335217229230$ Present evidence indicates that chondrocytes replicate in this model $^{32}$ similar to other injury models such as papain $^{109}$ or trypsin ${ }^{119}$ and that cartilage hypertrophy occurs because of an increase in water content accompanied by an increase in proteoglycan swelling, synthesis, and extractability. ${ }^{230}$ Cartilage hypertrophy related to oedema is an early feature of human osteoarthritis, ${ }^{231}$ particularly in articular cartilage volumes subject to increased biomechanical stress. In established osteoarthritis, however, cartilage hypertrophy present in both weight bearing and non weight bearing sites may relate more closely to its collagenous architecture than to its proteoglycan content. These compositional differences can be assessed in appropriate models of polyarticular structural arthroses.

To assess joint tissue composition before visible lesions are present, two new techniques are available: analytical MRI ${ }^{112} 220221232233$ and histological image analysis. ${ }^{234} \mathrm{MRI}$ can determine not only the volumes of joint soft tissues and cartilage but can assess water quality within joint cartilage. ${ }^{112} 220221232233$ Quantitation of histological data by image analysis can establish more precise topological relations between cells and extracellular matrix components of joint tissues. The application of confocal microscope with capabilities for three dimensional reconstruction of joint tissue architecture including the distribution of minor structural components, enzymes, and trace molecules holds particular promise. ${ }^{235}$ Serum and synovial fluid markers for clinical assessment of osteoarthritis are presently disappointing. However, in association with the production of specific lesions, animal models are becoming useful in the search for serum and synovial fluid markers of cartilage osteoarthritic activity. ${ }^{236-242}$

It is likely that greater precision in construction and analysis of osteoarthritic animal models will circumscribe and identify specific patterns of tissue composition in diseased joints. This will facilitate distinction of patterns associated with genetic, constitutional and biomechanical determinants of osteoarthritis from each other and from those of normal ageing. Now that new and more precise methods of assessing tissue composition are available, correlation of tissue patterns with osteoarthritis determinants is dependent on more precise characterisation of each determinant. Ambitious as this may seem, several promising approaches exist or appear to be on the near horizon. Genetic analysis of spontaneous osteoarthritis models is now available by DNA fingerprinting. ${ }^{243}$ It is now feasible to induce selected molecular defects in structural proteins such as collagen by genomic manipulation of transgenic mice. ${ }^{244}$ Structural arthroses can be induced selectively to affect certain extracellular matrix components or via cytokines and other mediators to modulate a restricted range of articular cell activity. ${ }^{145} 146$ Spontaneous osteoarthritis models can be used to assess each tissue change as osteoarthritis develops. These changes can be compared with 
both age matched controls and to changes in human disease. As knowledge develops, the role of systemic factors that affect osteoarthritis activity or progression can be tested in these models. As biomechanical models become more refined, these studies will relate the applied forces to mechanisms of absorbed energy dissipation including changes in matrix water movement, conformation of matrix macromolecules and articular cell activity. Clearly, biomechanical and structural arthroses are complementary models for osteoarthritis. Emerging from future research with animal models, we can expect a better understanding not only of osteoarthritis oetiopathogenesis but also of joint biology in general.

Drs Tony Cruz, Rita Kandel and Marc Grynpas provided many helpful discussions.

The author is grateful to the Arthritis Society of Canada and the Medical Research Council of Canada for the financial support of degenerative arthritis research in our laboratory and support of degenerative arthritis research in our laboratory

1 Richardson J. A primer of model systems. In: Richardson J, ed. Models of reality. Mt Airy: Lomond Publications, 1984: $1-8$

2 Wessler S L. Animal models of thrombosis and hemorrhagic diseases. 2nd ed. USA: DHEW Publications, 1976: xi-xvi.

3 Frenkel J K. Introduction: choice of animal models for the study of disease processes in man. Federation Proceedings, 1969: 160-1.

4 Hochberg M. Epidemiologic considerations in the primary prevention of osteoarthritis. I Rheumatol 1991; 18: prevention.

5 Moskowitz $\mathrm{R}$ W, Goldberg V M. Osteoarthritis. In: Schumacher $\mathrm{H}$ R, Klippel J H, Robinson D R, eds. Primer
on the rheumatic diseases, 9th ed. Atlanta, GA: Arthritis on the rheumatic diseases, 9
Foundation, $1988: 171-7$.

6 Burkhardt D, Ghosh P. Laboratory evaluation of antiarthritic drugs as potential chondroprotective agents. Semin Arthritis Rheum 1987; 17 (suppl 1): 3-34

7 Ghosh P, Smith M, Wells C. Second-line agents in osteoarthritis. In: Dixon J S, Furst D E, eds. Second-line agents in the treatment of rheum

Dekker, 1992; 363-427.

8 Mazieres B, Vignon E, Annefeld M. Les modéles animaux d'arthrose pour l'evaluation d'un médicament antiarthrosique. Rev Rhum 1990; 57: 19S-21S.

9 Mammalian models for research on aging. Washington, DC: National Academy Press, 1981: 1-6.

10 Altman R D, Dean D D. Osteoarthritis research: animal models. Semin Arthritis Rheu 1990; 19: 21-5.

11 Kandel R A, Renlund R C, Cheng P T, Rapley W A Mehren K G, Pritzker K P H. Calcium pyrophosphate dihydrate crystal deposition disease with concurrent vertebral hypertosis in a barbary ape. Arthritis Rheum vertebral hypert

12 Renlund R C, Pritzker K P H, Kessler M J. Rhesus monkey (macaca mulatta) as a model for calcium pyrophosphate
dihydrate crystal deposition disease. 7 Med Primatol 1986 ; dihydrate $11-6$.

13 Pritzker K P H, Chateauvert J, Grynpas M D, Renlund R C, Turnquist J, Kessler M J. Rhesus macaques as an experimental model for degenerative arthritis. Puerto Rico f Health Sciences 1989; 8: 99-102.

14 Troyer H. Experimental models of osteoarthritis: a review. Semin Arthritis Rheu 1982; 11: 362-74.

15 Adams M E, Billingham M E J. Animal models of degenerative joint disease. Curr Top Pathol 1982; 71: 265-97.

16 Adams M E, Pelletier J P. Canine anterior ligament transection model of osteoarthritis. In: Greenwald R A Diamond H S, eds. Handbook of animal models for the rheumatic diseases. Boca Raton, Florida: CRC Press, 1988 $57-81$.

17 Gardner D L. The experimental production of arthritis. Ann Rheum Dis 1960; 19: 297-317.

18 Bentley G. Experimental osteoarthrosis. In: Ali S Y, Elves M W, Leaback D H, eds. Proc syposium on normal and osteoarthrotic articular cartilage, 5-7 Nov 1973. The Institute of Orthopaedics, 1973: 259-83.

19 Arlet J, Gédéon P. Arthroses experimentales. Rev Rhum Mal Osteoartic 1982; 49: 145-52.

20 Moskowitz R W. Experimental models of degenerative joint disease. Semin Arthritis Rheu 1972; 1: 95-1 16

21 Moskowitz R W. Experimental models of osteoarthritis. Moskowitz R W. Experimental models of osteoarthritis. In: Moskowitz R W, ed. Osteoarthritts: diagnosis and management $213-32$.

22 Bennett G A, Bauer W. A study of the repair of the articular cartilage and the reaction of normal joints of adult dogs cartilage and the reaction of normal joints of adult dogs to surgically created defects of articular cartilage, 'joint mice', and
23 Bruce J, Walmsley R. Excison of the patella; some experimental and anatomical observations. $\mathcal{F}$ Bone foint Surg 1942; 24: 311-25.

24 Pond M J, Nuki G. Experimentally induced osteoarthritis in the dog. Ann Rheum Dis 1973; 32: 387-8.

25 Paatsama S. Ligament injuries in the canine stifle joint. A clinical and experimental study. Thesis: Helsinki University Finland, 1952.

26 Moskowitz R W, Davis W, Sammarco J, et al. Experimentally induced degenerative joint lesions following partial meniscectomy in the rabbit. Arthritis Rheum 1973; 16: $397-405$

27 DiPasquale G, Caputo C B, Crissman J W. Rabbit partial medial meniscectomy. In: Greenwald R A, Diamond H S, eds. Handbook of animal models for the rheumatic diseases, vol II. Boca Raton, Florida: CRC Press, 1988: 19-25.

28 Colombo C. Partial lateral meniscectomy with section of fibular collateral and sesamoid ligaments in the rabbit. In: Greenwald R A, Diamond H S, eds. Handbook of animal models for the rheumatic diseases, vol II. Boca Raton, Florida CRC Press, 1988: 27-55.

29 Colombo C, Butler M, O'Byrne E, et al. A new model of osteoarthritis in rabbits. Arthritis Rheum 1983; 26: 875-86

30 Moskowitz R W, Goldberg V M. Studies of osteophyte pathogenesis in experimentally induced osteoarthritis. f Rheumatol 1987; 14: 311-20.

31 Malemund C J. The biology of cartilage and synovium in animal models of osteoarthritis. In: Greenwald $\mathrm{R} \mathrm{A}$, Diamond H S, eds. Handbook of animal models for the rheumatic diseases, vol II. Boca Raton, Florida: CRC Press, 1988: 3-18.

32 Vignon E, Arlot M, Hartmann D, Moyen B, Ville G. Hypertrophic repair of articular cartilage in experimental osteoarthrosis. Ann Rheum Dis 1983; 42: 82-8.

33 Brandt K D. Transection of the anterior cruciate ligament in the dog: a model of osteoarthritis. Semin Arthritis Rheu 1991; 21: 22-32.

34 Hede A, Svalastoga E, Reimann I. Articular cartilage changes following meniscal lesions. Acta Orthop Scand 1991; 62: 319-22.

35 Brandt K D, Braunstein E M, Visco D M, O'Connor B, Heck D, Albrecht $M$. Anterior (cranial) cruciate ligament transection in the dog: a bona fide model of osteoarthritis, not merely of cartilage injury and repair. $尹$ Rheumatol not merely of car

36 Pelletier J P, Mineau F, Faure M P, Martel-Pelletier J. Imbalance between the mechanisms of activation and inhibition of metalloproteases in the early lesions of experimental osteoarthritis. Arthritis Rheum 1990; 33: 1466-76.

37 Ford C R, Gardner D L, O'Connor P. Ultrastructural changes in dog femoral condylar cartilage following anterior cruciate ligament section. f Anat 1983; 137: anterior

38 Orford $C \mathrm{R}$ Gardener $\mathrm{D} L$ O'Connor P, Bates $G$ Swallow J J, Brito-Babapulle L A P. Ultrastructural alterations in glycosaminoglycans of dog femoral condylar cartilage after surgical division of an anterior cruciate ligament: a study with cupromeronic blue in a critical electrolyte concentration technique. I Anat 1986; 148: 233-44.

39 Altman R D, Tenenbaum J, Latta L, Riskin W, Blanco L N, Howell D S. Biomechanical and biochemical properties of dog cartilage in experimentally induced osteoarthritis. Ann Rheum Dis 1984; 43: 83-90.

40 Sandy J D, Adams M E, Billingham M E J, Plaas A Muir H. In vivo and in vitro stimulation of chondrocyte Muir $\mathrm{H}$. In vivo and in vitro stimulation of chondrocyte
biosynthetic activity in early experimental osteoarthritis. biosynthetic activity in early experim
Arthritis Rheum 1984; 27: 388-97.

41 Pelletier J P, Martel-Pelletier J, Malemud C J. Canine osteoarthritis: effects of endogenous neutral metalloproteoglycanases on articular cartilage proteoglycans. f Orthop Res 1988; 6: 379-88.

42 Abatangelo G, Botti P, Del Bue M, et al. Intraarticular sodium hyaluronate injections in the Pond-Nuki experimental model of osteoarthritis in dogs. Clin Orthop 1989; 241: $278-41$.

43 Pelletier J P, Martel-Pelletier J, Mehraban F, Malemud C J. Immunological analysis of proteoglycan structural changes in the early stage of experimental osteoarthritic canine cartilage lesions. F Orthop Res 1992 10: 511-23.

44 Pelletier J P, Martel-Pelletier J, Ghandur-Mnaymneh L, Howell D S, Woessner J F Jr. Role of synovial membrane inflammation in cartilage matrix breakdown in the PondNuki dog model of osteoarthritis. Arthritis Rheum 1985; 28: 554-61.

45 Yu L P Jr, Smith G N, Brandt K D, Myers S L, O'Connor B L, Brandt D A. Reduction of the severity of canine osteoarthritis by prophylactic treatment with oral doxycycline. Arthritis Rheum 1992; 35: 1150-9.

46 Ratcliffe A, Rosenwasser M P, Mahmud F, et al. The in vivo effects of naproxen on canine experimental osteoarthritic articular cartilage: composition, metalloarthitic articular cartilage. composition, metalloproteinase activities and metabolism. In: van den Foint destruction in arthritis and osteoarthritis. Verlag, Basel: foint destruction in arthritis

47 Setton L A, Mow V C, Muller F J, Pita J C, Howell D S. Altered structure-function relationships for articular cartilage in human osteoarthritis and an experimental canine model. In. van den Berg W B, van der Kraan P M van Lent P L E M, eds. Foint destruction in arthritis
osteoarthritis. Verlag, Basel: Birkhauser, 1993: 27-48. 
48 Ghosh P, Armstrong S, Read R, et al. Animal models of early osteoarthritis: their use for the evaluation of potential chondroprotective agents. In: van den Berg W B, van der Kraan P M, van Lent P L E M. foint destruction in arthritis and osteoarthritis. Verlag, Basel: Birkhauser, 1993: 195-206.

49 Rosner I A, Goldberg V M, Getzy L, Moskowitz R W. Effects of estrogen on cartilage and experimentally induced osteoarthritis. Arthritis Rheum 1979; 22: 52-8.

50 Rosner I A, Malemud C J, Goldberg V M, Papay R S, Getzy L, Moskowitz R W. Pathologic and metabolic responses of experimental osteoarthritis to estradiol and responses of experimental osteoarthritis to estradiol and

51 Carreno M R, Muniz O E, Howell D S. The effect of glycosaminoglycan polysulfuric acid ester on articular cartilage in experimental osteoarthritis: effects on morphological variables of disease severity. $\mathcal{f}$ Rheumatol 1986; 13: 490-7.

52 Dean D D, Muniz O E, Rodriquez I, et al. Amelioration of lapine osteoarthritis by treatment with glycosaminoglycan-peptide association complex (Rumalon). Arthritis Rheum 1991; 34: 304-13.

53 Schwartz E R, Oh W H, Leveille C R. Experimentally induced osteoarthritis in guinea pigs. Arthritis Rheum 1981; 24: 1345-54

54 Schwartz E R. Surgically induced osteoarthritis in guinea pigs. In: Greenwald R A, Diamond H S, eds. Handbook of animal models for the rheumatic diseases, vol II. Boca Raton, Florida: CRC Press, 1988: 89-95.

55 Palmoski M J, Brandt K D. Immobilization of the knee prevents osteoarthritis after anterior cruciate ligament transection. Arthritis Rheum 1982; 25: 1201-8.

56 Palmoski M J, Bean J S. Cartilage atrophy induced by limb immobilization. In: Greenwald R A, Diamond H S, eds. Handbook of animal models for the rheumatic diseases, vol II. Boca Raton, Florida: CRC Press, 1988: 83-7.

57 Lukoschek M, Schaffler M B, Burr D B, Boyd R D, Lukoschek M, Schaffler M B, Burr D B, Boyd R D, Radin E L. Synovial membrane and cartilage changes in

58 Myers S L, Brandt K D. Synovitis and osteoarthritic changes in canine articular cartilage after anterior cruciate ligament transection. Arthritis Rheum 1990; 33: 1406-15.

59 Kofoed H. Hemodynamics and metabolism in arthrosis. Acta Orthop Scand 1986; 57: 119-22.

60 Arsever C L, Bole G G. Experimental osteoarthritis induced by selective myectomy and tendotomy. Arthritis Rheum 1986; 29: 251-61.

61 Layton M W, Goldstein S A, Goulet R W, Feldkamp L A, Kubinski D J, Bole G G. Examination of subchondral bone architecture in experimental osteoarthritis by microscopic computed axial tomography. Arthritis Rheum 1988; 31: $1400-5$.

62 O'Connor B L, Palmoski M J, Brandt K D. Neurogenic acceleration of degenerative joint lesions. $\mathcal{f}$ Bone foint Surg 1985; 67A: 562-72.

63 Pelletier J P, Pelletier J M. Protective effects of corticosteroids on cartilage lesions and osteophyte formation in the Pond-Nuki dog model of osteoarthritis. Arthritis Rheum 1989; 32: 181-93.

64 Reimann I. Experimental osteoarthrosis of the knee in rabbits induced by alteration of the load-bearing. Acta rabbits induced by alteration
Orthop Scand 1973; 44: 496.

65 Franz R, Fengler H, Arnold K. Der start des arthrotischen prozesses nach herstellung einer definierten praasrthro-
tischen deformitat in vier experimentellen untertischen deformitat in vier experimentellen unt
suchungen. Beitr Orthop Traumatol 1979; 26: 363-70.

66 Johnson R G, Poole A R. Degenerative changes in dog articular cartilage induced by a unilateral tibial valgus osteotomy. Exp Pathol 1988; 33: 145-64.

67 Inerot S, Heinegard D, Olsson S E, Telhag H, Audell L. Proteoglycan alterations during developing experimental osteoarthritis in a novel hip joint model. $f$ Orthop Res 1991; 9: 658-73.

68 Ely L W, Mensor M C. Studies on the immobilization of normal joints. Surg Gynecol Obstet 1933; 57: 212-5.

69 Evans E B, Eggers G W N, Butler J K, Blumel J. Experimental immobilization and remobilization of rat knee joints. F Bone foint Surg 1960; 42: 737-58.

70 Eronen I, Videman T, Friman C, Michelsson J E. Glycosaminoglycan metabolism in experimental osteoarthrosis caused by immobilization. Acta Orthop Scand 1978; 49: 329-34.

71 Videman T. Experimental osteoarthritis in the rabbit. Acta Orthop Scand 1982; 53: 339-47.

72 Salter R B, Simmonds D R, Malcolm B W, Rumble E J, MacMichael D, Clements N D. The biological effect of continuous passive motion on the healing of full-thickness defects in articular cartilage. F Bone foint Surg 1980; 62A: defects in

73 Salter R B. Continuous passive motion. Baltimore: Williams and Wilkins, 1993: 1-419.

74 Konttinen Y T, Michelsson J E, Tolvanen E, Bergroth V. Primary inflammatory reaction in synovial fluid and tissue in rabbit immobilization osteoarthritis. Clin Orthop 1990; 260: 280-6.

75 Troyer H. The effect of short-term immobilization on the rabbit knee joint cartilage. Clin Orthop 1975; 107: 249-57.

76 Candolin T, Videman T. Surface changes in the articular cartilage of rabbit knee during immobilization. A scanning electron microscopic study of experimental osteoarthritis. Acta Pathol Microbiol Scand $[A]$ 1980; 88: 291-7.

77 Behrens F, Kraft E L, Oegema T R Jr. Biochemical changes in articular cartilage after joint immobilization by casting or external fixation. F Orthop Res 1989; 7: 335-43.
78 Jurvelin J, Helminen $\mathrm{H} \mathrm{J}$, Lauritsalo S, et al. Influences of joint immobilization and running exercise on articular cartilage surfaces of young rabbits. Acta Anat 1985; 122: 62-8.

79 Halbrecht J, Carlstedt C A, Parsons J R, Grande D A. The influence of growth hormone on the reversibility of articular cartilage degeneration in rabbits. Clin Orthop 1990; 259: 245-55.

80 Palmoski M J, Brandt K D. Running inhibits the reversal of atrophic changes in canine knee cartilage after removal of a leg cast. Arthritis Rheum 1981; 24: 1329-37.

81 Palmoski M J, Brandt K D. Aspirin aggravates the degeneration canine joint cartilage caused by
immobilization. Arthritis Rheum 1982; 25: 1333-42.

82 Saamanen A M, Tammi M, Jurvelin J, Kiviranta I, Helminen $H$ J. Proteoglycan alterations following immobilization and remobilization in the articular cartilage of young canine knee (stifle) joint. F Orthop Res 1990; 8: 863-73.

83 Helminen H J, Kiviranta I, Säämänen A M, et al. Effect of motion and load on articular cartilage in animal models. In: Kuettner K E, Schleyerbach R, Peyron J G, Hascall V C, eds. Articular cartilage and osteoarthritis. New York: Raven Press 1992; 501-10.

84 Radin E L, Ehrlich M G, Chernack R, Abernethy P, Paul I L, Rose R M. Effect of repetitive impulsive loading on the knee joints of rabbits. Clin Orthop 1978; 131: 288-93.

85 Dekel S, Weissman S L. Joint changes after overuse and peak overloading of rabbit knees in vivo. Acta Orthop Scand 1978; 49: 519-28.

86 Radin E L, Rose R M. Role of subchondral bone in the initiation and progression of cartilage damage. Clin Orthop 1986; 213: 241-8.

87 Radin E L, Burr D B, Caterson B, Fyhrie D, Brown T D, Boyd R D. Mechanical determinants of osteoarthrosis. Semin Arthritis Rheu 1991; 3 (suppl 2): 12-21.

88 Thompson R C, Oegema T R, Lewis J L, Wallace L. Osteoarthrotic changes after acute transarticular load. f Bone foint Surg 1991; 73A: 990-1001.

89 Sokoloff L. Comparative pathology of arthritis. Adv Vet Sci Comp Med 1960; 6: 193-250.

90 Radin E L. Biomechanical considerations. In: Moskowitz R W, Howell D S, Goldberg V M, Mankin H J, eds. Osteoarthritis diagnosis and management. Philadelphia: W B Saunders, 1984: 93-107.

91 Walker E R, Boyd R D, Wu D D, Lukoschek M, Burr D B, Radin E L. Morphologic and morphometric changes in synovial membrane associated with mechanically induced osteoarthrosis. Arthritis Rheum 1991; 34: anically

92 Bartel D L, Bicknell V L, Ithaca M S, Wright T M. The effect of conformity. Thickness and material on stresses in ultra-high molecular weight components for total joint replacement. F Bone foint Surg 1986; 68A: 1041-51.

93 Ghadially J A, Ghadially R, Ghadially F N. Long-term results of deep defects in articular cartilage. Virchows Arch [B] 1977; 25: 125-36.

94 Cheung H S, Lynch K L, Johnson R P, Brewer B J. In vitro synthesis of tissue-specific type II collagen by healing cartilage. Arthritis Rheum 1980; 23: 211-9.

95 Furukawa T, Eyre D R, Koide S, Glimcher M J. Biochemical studies on repair cartilage resurfacing experimental defects in the rabbit knee. 7 Bone foint Surg 1980; 62A: 79-89.

$96 \mathrm{Kim} \mathrm{H} \mathrm{K,} \mathrm{Moran} \mathrm{M} \mathrm{E,} \mathrm{Salter} \mathrm{R} \mathrm{W.} \mathrm{The} \mathrm{potential} \mathrm{for}$ regeneration of articular cartilage in defects created by chondral shaving and subchondral abrasion. $f$ Bone foint Surg 1991; 73A: 1301-15.

97 Altman R D, Kates J, Chun L E, Dean D D, Eyre D. Preliminary observations of chondral abrasion in a canine model. Ann Rheum Dis 1992; 51: 1056-62.

98 Gédéon P, Mazières B, Ficat P. Un nouveau modele d'arthrose experimentale: la contusion du cartilage. Rev Rhum Mal Osteoartic 1978; 45: 401-8.

99 Simon W H, Richardson S, Herman W, Parsons J R, Lane J. Long-term effects of chondrocyte death on rabbit Lane J. Long-term effects of chondrocyte death on rabbit articular

100 Weinberger A, Schumacher H R. Experimental joint trauma: synovial response to blunt trauma and inflammatory reaction to intraarticular injection of fat. f Rheumatol 1981; 8: 380-9.

101 Hjertquist S O, Lemperg R. Histological, autoradiographic and microchemical studies of spontaneously healing osteochondral articular defects in adult rabbits. Calcif Tissue Res 1971;8: 54-72.

102 Ghadially F N, Fuller J A, Kirkaldy-Willis W H. Ultrastructure of full-thickness defects in articular cartilage. structure of full-thickness defect

103 Wolff D A, Stevenson S, Goldberg V M. S-100 Protein immunostaining identifies cells expressing a chondrocytic phenotype during articular cartilage repair. $\mathcal{F}$ Orthop Res 1992; 10: 49-57.

04 Cheung H S, Cottrell W H, Stephenson K, Nimni M E. In vitro collagen biosynthesis in healing and normal rabbit articular cartilage. $\mathcal{F}$ Bone foint Surg 1978; 60A: 1076-81.

$105 \mathrm{Key} \mathrm{J} \mathrm{A.} \mathrm{The} \mathrm{production} \mathrm{of} \mathrm{chronic} \mathrm{arthritis} \mathrm{by} \mathrm{the}$ injection of weak acids, alkalies, distilled water, and salt solution into joints. F Bone foint Surg 1933; 15; 67-84.

106 Murray D G. Experimentally induced arthritis using intraarticular papain. Arthritis Rheum 1964; 7: 21 1-9.

107 Havdrup T, Telhag H. Papain-induced changes in the knee joints of adult rabbits. Acta Orthop Scand 1977; 48: 143-9. 
108 Williams J M, Downey C, Thonar E. Increase in levels of serum keratan sulfate following cartilage proteoglycan degradation in the rabbit knee joint. Arthritis Rheum 1988; 31: $557-60$.

109 Havdrup T, Henricson A, Telhag H. Papain-induced mitosis of chondrocytes in adult joint cartilage. Acta Orthop Scand 1982; 53: 119-24.

110 Moriizumi T, Yamashita N, Okada Y. Papain-induced changes in the guinea pig knee joint with special reference to cartilage healing. Virchows Arch [B] 1986; 51: 461-74.

111 van der Kraan P M, Vitters E L, van der Putte L B A, van den Berg W B. Development of osteoarthritic lesions in mice by 'metabolic' and 'mechanical' alterations in in mice by 'metabolic' and 'mechanical' al
knee joints. Am ₹ Pathol 1989; 135: 1001-14

112 Paul P K, O'Byrne E, Blancuzzi V, et al. Magnetic resonance imaging reflects cartilage proteoglycan degradation in the rabbit knee. Skeletal Radiol 1991; 20: 31-6.

113 Williams J M, Uebelhart D, Ongchi D R, Kuettner K E, Thonar E J M A. Animal models of articular cartilage repair. In: Kuettner K E, Schleverbach R, Peyron J G, Hascall V C, eds. Articular cartilage and osteoarthritis. New York: Raven Press, 1992: 511-26.

114 Shaw N E, Lacey E. The influence of corticosteroids on normal and papain-treated articular cartilage in the rabbit. F Bone foint Surg 1973; 55B: 197-205.

115 van der Kraan $P$ M, Vitters E $L$, van Beuningen $H M$, van den Berg W B. proteoglycan synthesis and osteophyte formation in 'metabolically' and 'mechanically' induced murine degenerative joint disease: an in-vivo autoradiographic study. Int $\mathcal{F}$ Exp Path 1992; 73: 335-50.

116 Coulais Y, Marcelon G, Cros J, Guiraud R. Etude d'un modele experimental d'arthrose. Path Biol 1983; 31: 577-82.

117 Bentley G. Papain induced degenerative arthritis of the hip. F Bone foint Surg 1971; 53B: 324-37.

118 Lack W, Bosch P, Lintner F. Influence of trypsin on the regeneration of hyaline articular cartilage. Acta Orthop Scand 1986; 57: 123-5.

119 Havdrup T. Trypsin-induced mitosis in the articular cartilage of adult rabbits. Acta Orthop Scand 1979; 50: 15-9.

120 Renlund R C. Hyaluronidase arthropathy. MSc thesis, University of Toronto. 1980: 1-63.

121 van der Kraan P M, Vitters E L, van Beuningen $H$ M, van der Putte $\mathrm{L}$ B A, van den Berg W B. Degenerative knee joint lesions in mice after a single intraarticular collagenase injection: a new model of osteoarthritis. $\mathcal{F}$ Exp collagenase injection: a
Pathol 1990; 71: 19-31.

122 Skrivankova B, Julis I, Podrazky V, Trnavsky K. Effect of Rumalon (glycosaminoglycan-peptide) on the articular tissue. In: van den Berg W B, van der Kraan P M, van Lent $\mathrm{P}$ L E M, eds. Foint destruction in arthritis and osteoarthritis. Verlag, Basel: Birkhauser, 1993: 219-24.

123 Hugenberg S T, Myers S L, Brandt K D. Suppression of glycosaminoglycan synthesis by articular cartilage, but not of hyaluronic acid synthesis by synovium, after exposure to radiation. Arthritis Rheum 1989; 32: 468-74.

124 Mankin H J, Lipiello L. Acute metabolic effects on nitrogen mustard and thiotepa on rabbit articular cartilage
and synovium. Arthritis Rheum 1979;22: 579-85.

125 Frankl V, Pogrund H, Yosipovitch Z. The effect of intraarticular colchicine on the knee joint of the rat. Clin Orthop 1983; 178: 270-5.

126 Lagier R, MacGee W, Boussina I. Synovial deposit of osmic acid after intra-articular injection. Virchows Arch [Pathol Anat] 1976; 372: 237-44.

127 Bendele A M, Bean J S, Hulman J F. Passive role of articular chondrocytes in the pathogenesis of acute meniscectomy-induced cartilage degeneration. Vet Pathol 1991; 28: 207-15.

128 Lenzi L, Berlanda P, Flora A, et al. Vitamin A induced osteoarthritis in rabbits: an experimental model for
the study of human disease. In: Ali S Y, Elves $M \mathrm{~W}$, the study of human disease. In: Ali $\mathrm{S} \mathrm{Y}$, Elves $\mathrm{M}$,
Leaback $\mathrm{D} \mathrm{H}$, eds. Proc symposium on normal and osteoarthrotic articular cartilage, $5-7$ Nov 1973. The Institute of Orthpaedics, 1973: 243-57

129 Muirden K D, Phillips M. Evidence for a direct effect on articular cartilage and its lysosomal enzymes in filipininduced arthritis. Arthritis Rheum 1976; 19: 251-61.

130 Van Sickle D C. Experimental models of osteoarthritis. In: eds. Scarpelli D G, Migaki G. Comparative pathobiology of major age-related diseases: current status and research of major age-related diseases: current status and

131 Mehta P N, Ghadially F N. Articular cartilage in corn oilMehta P N, Ghadially F N. Articular cartilage in corn oil-
induced lipoarthrosis. Ann Rheum Dis 1973; 32: 75-82.

132 Deshmukh K, Hemrick S. Metabolic changes in rabbit articular cartilage due to inflammation. Arthritis Rheum articular cartilage due

133 Ghadially F N, Janzen H K, Mehta P N. Synovial membrane in experimental lipoarthrosis. Arch Pathol 1970; 89: 291-301.

134 Lowther D A, Gillard G C. Carrageenin-induced arthritis. The effect of intraarticular carrageenin on the chemical composition of articular cartilage. Arthritis Rheum 1976; 19: $769-76$.

135 Soballe K, Pedersen C M, Odgaard A, et al. Physical bone changes in carrageenin-induced arthritis evaluated by quantitative computed tomography. Skeletal Radiol 1991; 20: 345-52.

136 Holm I E, Bunger C, Melsen F. A histomorphometric analysis of subchondral bone in juvenile arthropathy of the dog knee. Acta Pathol Microbiol Scand [A] 1985; 93: 299-304.
137 van den Berg W B, Kruijsen M W M, van de Putte L B A, van Beusekom $\mathrm{H} J$, van der Sluis-van der Pol $M$, Zwarts W A. Antigen-induced and zymosan-induced arthritis in mice: studies on in vivo cartilage proteoglycan
synthesis and chondrocyte death. Br F Exp Pathol 1981; 62: 308-16.

138 Schalkwijk J, Joosten L A B, van den Berg W B, van de Putte L B A. Chondrocyte nonresponsiveness to insulinlike growth factor 1 in experimental arthritis. Arthritis like growth factor 1 in exper
Rheum 1989; 32: 894-900.

139 Keystone E C., Schorlemmer H U, Pope C, Allison A C. Zymosan-induced arthritis: A model of chronic proliferative arthritis following activation of the alternative pathway of complement. Arthritis Rhutum 1977; 20: 1396-401.

140 Steinberg J, Sledge G B, Noble J, Gillies H G. Dextran sulphate induced arthritis in rabbits. Ann Rheum Dis 1980; 39: 387-91.

141 Evans C H, Mazzocchi R A, Nelson D D, Rubash H E. Experimental arthritis induced by intraarticular injection of allogenic particles into rabbit knees. Arthritis Rheum 1984; 27: 200-7.

142 Smith R L, Schurman D J, Kajiyama G, Mell M, Gilkerson E. The effect of antibiotics on the destruction of cartilage in experimental infectious arthritis. 7 Bone foint Surg 1987; 69A: 1063-8.

143 Pettipher E R, Higgs G A, Henderson B. Interleukin 1 induces leukocyte infiltration and cartilage proteoglycan degradation in the synovial joint. Proc Natl Acad Sci USA 1986; 83: 8749-53.

144 van Beuningen $\mathrm{H} \mathrm{M}$, Arntz O J, van den Berg W B. In vivo effects of interleukin-1 on articular cartilage. Arthritis Rheum 1991; 34: 606-15.

145 Elford P R, Graeber M, Ohtsu $\mathrm{H}$, ol al Induction of swelling, synovial hyperplasia and cartilage proteoglycan
loss upon intra-articular injection of transforming growth loss upon intra-articular injection of transforming
factor- $\beta-2$ in the rabbit. Cvtok 1992; 4: 232-8.

146 O'Byrne E, Blancuzzi V, Wilson D E, Wong M, Jeng A Y. Elevated substance $P$ and accelerated cartilage degradation in rabbit knees injected with interlcukin-1 and tumor necrosis factor. Arthritis Rhcum 1990; 33: 1023-8.

147 van den Berg W B, van de Loo F A J, van Lent P L E M, Joosten L A B. Mechanisms of cartilage destruction in joint inflammation. In: van den Berg $W$ B , van der Kraan P M, van Lent P L E M, eds. Foint destruction in arthritis and osteoarthritis. Verlag, Basel: Birkhauser, 1993: arthritis at $49-60$.

148 Stevens P, Scott R W, Shatzen. Amgen E M. Recombinant human protease nexin-1 prevents articular cartilagedegradation in the rabbit. In: van den Berg W B, van der Kraan P M, van Lent P L E M, eds. Foint destruction in arthritis and osteoarthritis. Verlag, Basel: Birkhauser, 1993: $173-7$

149 Reginato A J, Schumacher H R Jr. Spontaneous and experimental articular and periarticular calcification. In: Greenwald R A, Diamond H S. eds. CRC handbook of animal models for the rheumatic diseases, vol II. Boca Raton, Florida: CRC Press, 1988: $127-48$.

150 Salter R B, Gross A, Hall J H. Hydrocortisone arthropathy an experimental investigation. Can Med Assoc f 1967; 97: 374 7

151 Behrens F, Shepard $N$, Mitchell N. Alteration of rabbit articular cartilage by intra-articular injections of glucocorticoids. $\mathcal{F}$ Bone foint Surg 1975; 57A: 70-6.

152 Behrens F, Shepard N, Mitchell N. Metabolic recovery of articular after intra-articular injections of glucocorticoid. f Bone foint Surg 1976; 58A: 1157-60

153 Tenenbaum J, Pritzker K P H, Gross A E, Cheng P T, Renlund R C, Tenenbaum H. The effects of intraarticular corticosteroids on articular cartilage. Semin Arthritis Rheum 1981; XI (suppl 1): 140-1.

154 Yosipovitch Z H, Glimcher M J. Articular chondrocalcinosis, hydroxyapatite deposition disease, in adult
mature rabbits. F Bone foint Surg 1972; 54A: 841-53.

155 Vasilev V, Merker H J, Vidinov N. Ultrastructural changes in the synovial membrane in experimentally-induced osteoarthritis. Histol Histopathol 1992; 7: 119-27.

156 Soren A, Klein W, Huth F. The synovial changes in posttraumatic synovitis and osteoarthritis. Rheumatol Rehabil $1978 ; 17: 38-45$

157 Fam A G, Schumacher H R Jr. Crystal-induced joint inflammation. In: Greenwald R A, Diamond H S. CRC handbook of animal models for the rheumatic diseases, vol II. Boca Raton, Florida: CRC Press, 1988: 99-125.

158 Gershuni D H, Axer A, Siegel B. Localized regressive articular cartilage changes in the hip joint of the rabbit articular cartilage changes in the hip joint of the rabbit
following an induced synovitis. Acta Orthop Scand 1979; following an $179-85$.

159 Gershuni D H, Kuei S C. Articular cartilage deformation following experimental synovitis in the rabbit hip. f Orthop Res 1984; 1: 313-8.

160 Gershuni D H, Amiel D, Gonsalves M, Akeson W H. The biochemical response of rabbit articular cartilage matrix to an induced talcum synovitis. Acta Orthop Scand 1981; 52: 599-603.

161 Cushnaghan J, Dieppe P. Study of 500 patients with limb joint osteoarthritis. I. Analysis by age, sex, and distribution of symptomatic joint sites. Ann Rheum Dis 1990; 50: 8-13.

162 Silberberg M, Silberberg R. Age changes of bones and joints in various strains of mice. Am f Anat 1941; 68: 69-95.

163 Silberberg M, Silberberg R. Effects of a high fat diet on the joint of aging mice. Arch Pathol 1950; 50: 828-46. 
164 Silberberg $M$, Silberberg $R$. Effects of 17-ethyl-19nortestosterone on articular ageing and osteoarthrosis in orchiectomized mice. $f$ Gerontol $1961 ; 16: 20-4$.

165 Silberberg R, Silberberg M. Male sex hormone and osteoarthrosis in mice. 7 Bone foint Surg $1961 ;$ 43A: $243-8$.

166 Silberberg R, Silberberg M. Pathogenesis of osteoarthrosis. Pathol Microbiol 1964; 27: 447-57.

167 Silberberg M, Silberberg R. Role of sex hormone in the pathogenesis of osteoarthrosis of mice. Lab Invest 1963; 12: $285-9$.

168 Silberberg R. Skeletal effects of cholesterol feeding. Patho Microbiol 1975; 43: 276-86.

169 Silberberg R, Hasler M. Submicroscopic response of articular chondrocytes to a cholesterol-containing diet. Pathol Microbiol 1975; 43: 276-86.

170 Pataki A, Wilhelmi G. Meniskusveränderungen bei der C57B1 Maus und ihre Bedeutung für die Pathogenese der spontanen Gonarthrose. Exp Rheum 1986; 167-72.

171 Pataki A, Fries R, Ochsner K, Witzemann E. Qualitative radiographic diagnosis of osteo-arthritis of the knee joint in the C57BL mouse. Agents Actions 1987; 22: 123-30.

172 Silberberg $M$, Silberberg R. Osteoarthrosis and osteoporosis in senile mice. Gerontologia 1962; 6: 91-101.

173 Lippiello L, Fienhold M, Grandjean C. Metabolic and ultrastructural changes in articular cartilage of rats fed dietary supplements of omega-3 fatty acids. Arthritis Rheum 1990; 33: 1029-36.

174 Burkhardt J E, Hill M A, Carlton W W, Kesterson J W. Histologic and histochemical changes in articula cartilages of immature beagle dogs dosed with difloxacin a fluoroquinolone. Vet Pathol 1990; 27: 162-70.

175 Gough A W, Kasali O B, Sigler R E, Baragi V. Quinolon arthropathy-acute toxicity to immature articular cartilage. Toxicol Pathol 1992; 20: 436-49.

176 Trentham D E, Townes A S, Kang A H. Autoimmunity to type II collagen: an experimental model of arthritis. f Exp Med 1977; 146: 857-68.

177 Dayer E, Mathai L, Glant T. Cartilage proteoglycaninduced arthritis in $\mathrm{BALB} / \mathrm{c}$ mice-antibodies that induced arthritis in BALB/c mice-antibodies that recognize human and mouse cartilage proteoglycan and can cause depletion of cartilage proteoglycan with litt
no synovitis. Arthritis Rheum 1990; 33: 1394-405.

178 DeSimone D P, Parsons D B, Johnson K E. Type It collagen-induced arthritis-a morphologic and bio chemical study of articular cartilage. Arthritis Rheum 1983; 26: 1245-58.

179 Bakker N P M, van Erck M G M, Botman C A D. Collagen-induced arthritis in an outbred group of rhesus monkeys comprising responder and nonresponder animals-relationship between the course of arthritis and collagen-specific immunity. Arthritis Rheum 1991; 34 collagen-

180 Sloboda A D, Birnbaum J E, Oronsky A L. Studies on type II collagen-induced polyarthritis in rats-effect of antiinflammatory and antirheumatic agents. Arthritis Rheum 1981; 24: 616-24

181 Pettipher E R, Henderson B, Hardingham T, Ratcliffe A Cartilage proteoglycan depletion in acute and chronic antigen-induced arthritis. Arthritis Rheum 1989; 32: 601-7.

182 Loutis N, Bruckner P, Pataki A. Induction of erosive arthritis in mice after passive transfer of anti-type II collagen antibodies. Agents Actions 1988; 25: 352-9.

183 Kawai K, Scudamore R A, Cooke T D V. An experimental polyarthritis associated with systemic antigen excess in immune rabbits. F Orthop Res 1983; 1: 144-52.

184 Rordorf C, Pataki A, Nogues V, Schlager F, Feige U, Glatt $M$. Arthritis in MRL/LPR mice and in collagen II sensitized DBA-1 mice and their use in pharmacology. Int f Tissue React 1987; ix(4): 341-7.

185 Walton $M$. Studies of degenerative joint disease in the mouse knee joint; scanning electron microscopy. 7 Pathol 1977; 123: 211-7.

186 Sokoloff L. Natural history of degenerative joint disease in small laboratory animals. 1 Pathologic anatomy of degenerative joint disease in mice. Arch Pathol 1956; 62: $118-28$

187 Sokoloff L. Natural history of degenerative joint disease in small laboratory animals. 2 Epiphyseal maturation and osteoarthritis of the knee of mice of inbred strain. Arch Pathol 1956; 62: 129-35.

188 Wigley R D, Couchman K G, Maule R, Reay B R. Degenerative arthritis in mice study of age and sex frequency in various strains with a genetic study of NZB/B1, NZY/B1, and hybrid mice. Ann Rheum Dis 1977; 36: 249-53.

189 Silverstein E, Sokoloff L. Natural history of degenerative joint disease in small laboratory animals. 5. Osteoarthritis in guinea pigs. Arthritis Rheum 1958; 1: 82-6.

190 Lust G, Geary J C, Sheffy B E. Development of hip dysplasia in dogs. Am $\mathcal{F}$ Vet Res 1973; 34: 87-9

essler M J, Grynpas M D. Spontaneous osteoarthritis in rhesus macaques. I. Chemical and biochemical studies. $\mathcal{F}$ Rheumatol 1989; 16: 1098-104.

192 Walton $M$. Naturally occurring osteoarthrosis in the mouse and other animals. In: Ali S Y, Elves M W, Leaback D H, eds. Proc symposium on normal and osteoathrotic articular cartilage, 5-7 Nov 1973. The Institute of Orthopaedics, 1973: 285-98.

193 Châteauvert J M D, Grynpas M D, Kessler M J, Pritzker K P H. Spontaneous osteoarthritis in rhesus macaques. II. Characterization of disease and morphometric studies. $\mathcal{f}$ Rheumatol 1990; 17: 73-83.
194 Lagier R. Hip osteoarthrosis in dogs with an acetabular dysplasia: a pathological study. $\mathcal{F}$ Orthop Rheum 1988; 1 219-26.

195 Olsewski J M, Lust G, Rendano V T, Summers B A Degenerative joint disease: multiple joint involvement in young and mature dogs. Am $\mathcal{F}$ Vet Res 1983; 44: 1300-8.

196 Mohr W, Lehmann H. Osteoarthrosis of the ankle joints in old rats. $Z$ Rheumatol 1991; 50: 359-65.

197 Rothschild B M, Woods R J. Osteoarthritis, calcium pyrophosphate deposition disease, and osseous infection in old world primates. Am f Phys Anthropol 1992; 87: 341-7.

198 DeRousseau C J. Aging in the musculoskeletal system of rhesus monkeys: II. Degenerative joint disease. $A m \mathcal{F} P h y s$ Anthropol 1985; 67: 177-84

199 DeRousseau C J. Osteoarthritis in rhesus monkeys and gibbons. Basel: Karger, 1988: 1-145.

200 Bridges P S. Degenerative joint disease in hunter-gatherer and agriculturalists from the southeastern United States. Am F Phys Anthropol 1991; 85: 379-91.

201 Mammalian models for research on aging. Washington, DC National Academy Press, 1981: 352-8.

202 Gibson J P, Roenigk W J. Pseudogout in a dog. 7 Am Vet Med Assoc 1972; 161: 912-5.

203 Sokoloff L. The Biology of Degenerative Joint Disease. London: The University of Chicago Press, 1969: 18-21.

204 Sokoloff L, Jay G E Jr. Natural history of degenerative joint disease in small laboratory animals. IV Degenerative join disease in the laboratory rat. Arch Pathol 1956; 62: 140-2.

205 Walton M. Patella displacement and osteoarthrosis of the knee joint in mice. F Pathol 1979; 127: 165-72.

206 Rostand K S, Baker J R, Caterson B, Christner J E. Articular cartilage proteoglycans from normal and osteoarthritic mice. Arthritis Rheum 1986; 29: 95-105.

207 Schünke $M$, Tillmann B, Brück $M$, Müller-Ruchholtz W. Morphologic characteristics of developing osteoarthrotic lesions in the knee cartilage of str/in mice. Arthritis Rheum 1988; 31: 898-905.

208 Livne E, von der Mark K, Silbermann M. Morphologic and cytochemical changes in maturing and osteoarthritic articular cartilage in the temporomandibular joint of mice. Arthritis Rheum 1985; 28: 1027-38.

209 Chen W H, Hosokawa M, Tsuboyama T, Ono T, Lizuka T, Takeda T. Age-related changes in the temporomandibular joint of the senescence accelerated mouse $\mathrm{SAM}-\mathrm{P} / 3$ as a new murine model of degenerative joint disease. Am F Pathol 1989; 135: 379-85.

210 Stanescu R, Knyszynski A, Muriel M P, Stanescu V. Early lesions of the articular surface in a strain of mice with very high incidence of spontaneous osteoarthritic-like lesions. Rheumatol 1993; 20: 102-10.

211 Mammalian models for research on aging. Washington, DC National Academy Press, 1981: 23-57.

212 Bendele A M, Hulman J F. Spontaneous cartilage degeneration in guinea pigs. Arthritis Rheum 1988; 31: 561-5.

213 Bendele A M, White S L, Hulman J F. Osteoarthrosis in guinea pigs: histopathologic and scanning electron microscopic features. Lab Anim Sci 1989; 39: 115-20.

214 Greisen H A, Summers B A, Lust G. Ultrastructure of the articular cartilage and synovium in the early stages of degenerative joint disease in canine hip joints. Am $7 \mathrm{Vet}$ degenerative joint disease

215 Burton-Wurster N, Lust G. Deposition of fibronectin in articular cartilage of canine osteoarthritic joints. $A m \mathcal{F}$ Vet Res 1985; 46: 2542-5.

216 Mammalian models for research on aging. Washington, DC National Academy Press, 1981: 75-82

217 Adams M E, Brandt K D. Hypertrophic repair of canine articular cartilage in osteoarthritis after anterior cruciate ligament transection. $\mathcal{F}$ Rheumatol 1991; 18: 428-35.

218 Roberts E D, Baskin G B, Watson E, Henk W G Shelton T C. Calcium pyrophosphate deposition disease. Am f Pathol 1984; 116: 359-61.

219 Pritzker K P H, Chateauvert J M D, Grynpas M D Kessler M J. Studies of naturally degenerative arthritis in rhesus macaques as a model for degenerative arthritis in man. In: Maroudas A, Kuettner K E, eds. Methods in cartilage research. London: Academic Press, 1990: 341-2. rhesus macaque osteoarthritis. In: eds. Kuettner $\mathrm{K} E$ Schleyerback R S, Peyron J G, Hasvall V C. Articular cartilage and osteoarthritis. New York: Raven Press, 1992: 473-85.

221 Gahunia $H$ K, Lemaire C, Cross A R, Kessler M J, Pritzker K P H. Osteoarthritis in rhesus macaques: assessment of cartilage matrix quality by quantitative magnetic resonance imaging. In: van den Berg W B, van der Kraan P M, van Lent P L E M, eds. Foint destruction in arthritis and osteoarthritis. Verlag, Basel: Birkhauser, 1993: 255-9.

222 Grynpas M D, Hancock R G V, Greenwood C, Turnquist J, Kessler M J. The effects of diet, age, and sex on the mineral content of primate bones. Calcif Tissue Int 1993; 52: 399-405.

223 Rawlins, R G, Kessler M J, ed. The Cayo Santiago Macaques: history behaviour and biology. Albany: State University of New York Press, 1986: 1-301

224 Kessler M J, ed. Proc 50th anniversary of Cayo Santiago rhesus monkey colony. Puerto Rico Health Services $\mathcal{F} 1989$; 8: $1-209$.

225 Merbs C F. Patterns of activity-induced pathology in a Canadian inuit population; archeological survey of Canada paper no 119. Natl Museums of Canada 1983: 
226 Carney S L, Billingham M E J, Caterson B, et al. Changes in proteoglycan turnover in experimental canine osteoin proteoglycan turnover in experimental

227 Bayliss M T. Metabolism of animal and human osteoarthritic cartilage. In: Kuettner K E, Schleyerbach R S, arthritic cartilage. In: Kuettner K E, Schleyerbach R S, Peyron J G, Hascall V C, eds. Articular cartilage

228 Sokoloff L. Animal models of osteoarthritis. $\mathcal{F}$ Rheumatol 1990; 17: 5-6.

229 Pritzker K P H. Posttraumatic cartilage hypertrophy: edema or repair? F Rheumatol 1991; 18: 314-5.

230 Adams M E. Cartilage hypertrophy following canine anterior cruciate ligament transection differs among different areas of the joint. 7 Rheumatol 1989; 16: 818-24.

231 Venn M, Maroudas A. Chemical composition and swelling of normal and osteoarthritic femoral head cartilage. Ann of normal and osteoarthritic

232 McKeag D, Smith B W H, Edminster R, Laird $T$ Clark J, Herron S. Estimating the severity of osteoarthritis with magnetic resonance spectroscopy. Semin Arthritis Rheu 1992; 21: 227-38.

233 Hodgson R J, Carpenter T A, Hall L D. Magnetic resonance imaging of osteoarthritis. In: Kuettner $\mathrm{K} \mathrm{E}$, Schleyerbach R, Pevron J G, Hascall V C, eds. Articular cartilage and ostevarthritis. New York: Raven Press, 1992 $629-42$.

234 Rubin A S, Roberts E D. Morphometric quantitation of histopathologic changes in articular cartilage in an immunologically-induced rabbit model of rheumatoid arthritis. Lab Invest 1987; 57: 342-6.

235 Wotton S F, Jeacocke R E, Maciewicz R A, Wardale R J Duance $V$ C. The application of scanning confocal microscopy in cartilage research. Histochem $\mathcal{f} 1991 ; 23$ 328-35.
236 Leipold H R, Goldberg R L, Lust G. Canine serum keratan sulfate and hyaluronate concentrations. Arthritis Rheum 1989; 32: 312-21.

237 Goldberg R L, Huff J P Lenz M E, Glickman P, Katz R, Thonar E J M A. Elevated plasma levels of hyaluronate in patients with osteoarthritis and rheumatoid arthritis. in patients with osteoarthritis and
Arthritis Rheum 1991; 34: 799-807.

238 Hedin P J, Weitoft T, Hedin H, Engström-Laurent A Saxne $T$. Serum concentrations of hyaluronan and proteoglycan in joint disease. Lack of association. f Rheumatol 1991; 18: 1602-5.

239 Saxne T, Heinegard D. Synovial fluid analysis of two groups of proteoglycan epitopes distinguishes early and late cartilage lesions. Arthritis Rheum 1992; 35: 385 90.

240 Lohmander L S. Molecular markers of cartilage turnover. In: Kuettner K E, Schleyerbach R, Peyron J G, Hascall V C, eds. Articular cartilage and ostcoarthritis. New York: Raven Press 1992: 653-67.

241 Williams J M, Downey $C$, Thonar E J M A. Increase in levels of serum keratan sulfate following cartilage proteoglycan degradation in the rabbit knee joint. Arthritis Rheum 1988; 4: 557-60

242 Ratcliffe A, Shurety W, Caterson B. The quantitation of a native chondroitin sulfate epitope in synovial fluid lavages and articular cartilage from canine experimental osteoarthritis and disuse atrophy. Arthritis Rheum 1993; 36: $543-51$

243 Weiss M L, Wilson V, Chan C, Turner T, Jeffrevs A J. Application of DNA fingerprinting probes to old world Application of DNimato 1988; 16: 73-9.

244 Scarpelli DG Migaki G, Pletcher JM, eds. Transgenic Animal Models in Biomedical Research. Washington, DC: American Registry of Pathology, Armed Forces Institute of Pathology, 1991. 